\title{
The differentiation of pluripotent stem cells towards transplantable endothelial progenitor cells
}

\section{Kezhou Qin ${ }^{1}$, Jun Yang ${ }^{1,2^{*}}$}

${ }^{1}$ Department of Cell Biology, Institute of Basic Medical Sciences, Chinese Academy of Medical Sciences \& Peking Union Medical College, 5 Dongdan San Tiao, Beijing 100005, China

${ }^{2}$ Department of Physiology, and Department of Cardiology of the Second Affiliated Hospital, Zhejiang University School of Medicine, Hangzhou 310058, Zhejiang, China

Corresponding Author: Jun Yang, Research Center of Molecular Medicine, Zhejiang University School of Medicine, 866 Yuhangtang Road, Hangzhou 310058, Zhejiang, China;

Email: yang_jun@zju.edu.cn (J.Y.); Telephone number: 0086-571-88208265 


\section{Abstract}

Endothelial progenitor cells (EPCs) and endothelial cells (ECs) have been applied in the clinic to treat pulmonary arterial hypertension (PAH), a disease characterized by disordered pulmonary vasculature. However, the lack of sufficient transplantable cells before the deterioration of disease condition is a current limitation to apply cell therapy in patients. It is necessary to differentiate pluripotent stem cells (PSCs) into EPCs and identify their characteristics. Comparing previously reported methods of human PSCs-derived ECs, we optimized a highly efficient differentiation protocol to obtain cells that match the phenotype of isolated EPCs from healthy donors. The protocol is compatible with chemically defined medium (CDM), it could produce a large number of clinically applicable cells with low cost. Moreover, we also found PSCs-derived EPCs express CD133, have some characteristics of mesenchymal stem cells and are capable of homing to repair blood vessels in zebrafish xenograft assays. In addition, we further revealed that IPAH PSCs-derived EPCs have higher expression of proliferation-related genes and lower expression of immune-related genes than normal EPCs and PSCs-derived EPCs through microarray analysis. In conclusion, we optimized a highly efficient differentiation protocol to obtain PSCs-derived EPCs with the phenotypic and molecular characteristics of EPCs from healthy donors which distinguished them from EPCs from $\mathrm{PAH}$.

Keywords: stem cell differentiation, endothelial cell, endothelial progenitor cell, pulmonary arterial hypertension 


\section{Introduction}

In hypoxic environments, endothelial cells (ECs) lining on the inner layer of blood vessel have the ability to modulate vascular tone and are involved in angiogenesis (Niskanen et al. 2018). Endothelial progenitor cells (EPCs) are one type of ECs which could be isolated from blood by colony expansion and have been demonstrated to promote ischaemic tissue angiogenesis (Zhao et al. 2019), so they are capable of facilitating vascular repair under different ischaemic conditions, such as acute myocardial infarction, unstable angina, stroke, diabetic micro vasculopathies, pulmonary arterial hypertension, atherosclerosis, and ischaemic retinopathies (Ward, Stewart, and Kutryk 2007; Jung and Roh 2008; Sekiguchi, Il, and Losordo 2009). Human ECs can only be obtained from dissected vessel after surgical moving it from body. Although EPCs can be isolated by our group with improved technique from only $20 \mathrm{~mL}$ blood, they still have limited expansion potential as ECs, are rare in peripheral or umbilical cord blood compared with other blood cells, which hinders the application of cell therapy in clinical treatment (Medina et al. 2012; Medina et al. 2010; Zhang, Chu, et al. 2017).

Human PSCs including embryo stem cells (ESCs) and induced pluripotent stem cells (iPSCs) can be induced to produce scalable endothelial cells and endothelial progenitor cells for vascular remodelling (Belair et al. 2015; James et al. 2010; Lian et al. 2014; Medina et al. 2010; Nguyen et al. 2016; Patsch et al. 2015; Prasain et al. 2014), and so far there have been two methods of inducing PSCs to differentiate into vascular cells, namely, embryoid body formation (Park et al. 2014; Park et al. 2019) and monolayer-directed differentiation (Prasain et al. 2014; Patsch et al. 2015; James et al. 2010) . In the former 
method, the cells need to be transferred into ultra-low-attachment plates to obtain embryoid bodies (EBs) to generate various types of cells, which is not cost-effective and is often time consuming (Han et al. 2018; Park et al. 2014). Monolayer differentiation methods have a higher differentiation efficiency (Patsch et al. 2015) than EBs methods, and have been the main methods for obtaining a large amount of functional ECs to repair vascular deficiencies, but it's necessary to further understand the complicated factors affecting EC differentiation.

Endothelial dysfunction has been thought to be the main contributor of PAH/IPAH. Some studies have reported that the numbers of $\mathrm{CD}_{133^{+}}$cells in peripheral blood increased in PAH/IPAH patients compared with controls (Foris et al. 2016; Toshner et al. 2009). Toshner et al. also demonstrated that PAH patient-derived endothelial progenitor cells have a hyperproliferative phenotype and a reduced capacity to form vascular networks (Toshner et al. 2009). However, recent results demonstrated that early EPCs overexpressing eNOS could be beneficial for the treatment of PAH (Gomberg-Maitland et al. 2013).

In this study, we aimed to explore the factors affecting vascular cell differentiation and to optimize a chemical method and cost-effective system for generating human PSCsderived EPCs through monolayer-directed differentiation, while also characterizing the molecular features of PSCs-derived EPCs, IPAH-derived EPCs and normal EPCs. We found that the Rock inhibitor Y27632 and DMSO markedly accelerated vascular mesoderm generation from PSCs and improved the differentiation efficiency. Then, the functions of these cells were tested in parallel by tube formation and LDL uptake assays, microarray 
analysis and cell transplantation in zebrafish. This optimized system can offer a simple, rational, cost-effective platform to produce PSCs-derived ECs/EPCs for vascular research and clinical application.

\section{Methods}

\subsection{Cell Maintenance}

Human ESCs (H9 and H1, WiCell Madison, WI, given by Roger Pedersen, University of Cambridge)/iPSCs(generated in house, reported previously by Fang, Zhou) were cultured in Essential 8 (E8) medium or mTeSR ${ }^{\mathrm{TM}} 1$ Complete Kit (Catalog \#85850) or hPSC$\mathrm{CDM}^{\mathrm{TM}}$ (Cauliscell Inc. \#400105) supplemented with hPSC-CDM ${ }^{\mathrm{TM}}$ supplement (Cauliscell Inc. \#600301) on Matrigel-coated (BD Bioscences, \#356230) 6-well plates and were passaged with $500 \mu \mathrm{M}$ EDTA for 3-5min. EPCs/ECs were maintained in EGM2+16\%FBS (HyClone) (Ormiston et al. 2015).

\subsection{Endothelial Cell Differentiation, Purification, and Culture}

When human ESCs/iPSCs grew to 80\%-90\% confluency, they were dissociated with Accutase (Gibco, \#A11105-01) and plated about $3 \times 10^{4}$ cells/well in vitronectin-coated (Cauliscell Inc.\#500125) 12-well plates, ESCs/iPSCs were differentiated into mesoderm cells by culturingin E8 medium (Gibco, A1516901) supplemented with 25ng/mL Activin A(R\&D, Catalog Number.338-AC), $10 \mu \mathrm{M}$ Y27632 (Sigma) and 10ng/mL BMP4(R\&D, Catalog Number.314-BP) for 3 days. Mesoderm cells were then cultured for 4 days in E6 medium (Gibco, A1516401) supplemented with FGF2 100ng/ml (R\&D, Catalog Number.233-FB), VEGF 50ng/mL (R\&D, Catalog Number.293-VE), BMP4 50ng/mL and 
SB431542 $5 \mu \mathrm{M}$ (Sigma-Aldrich, CAS 301836-41-9-Calbiochem) to generate endothelial cells, and the whole differentiation process continues 7 days. Cells were counted and the cell suspension was prepared for the isolation of endothelial cells. Endothelial cells were isolated by using CD31+ MicroBeads (Miltenyi Biotec, Order no.130-091-935) according to manufacturer' s instructions and cultured in EGM2 with 16\% FBS (HyClone).

\subsection{Flow cytometry}

At day 3 or 7 of differentiation, adherent cells were harvested using 0.25\% TrypleE with EDTA and made into a single-cell suspension in PBS with 0.2\% BSA; then all cells were analyzed using flow cytometry directly without purification. Mouse Anti-Human APJ APCconjugated Antibody(R\&D, Catalog Number: FAB8561A) was used as a ratio of 1: 50, Mouse IgG1 (FITC, Material Number:551954, BD Pharmingen), Mouse Anti-human CD31 (CD31-FITC, Material Number: 555824, BD Pharmingen), Mouse IgG1-APC (Order no:130092214, Miltenyi Biotec), Mouse Anti-human CD34 (CD34-APC, Material Number: 560940, BD Pharmingen), Mouse Anti-human CD43 (CD43-APC, Material Number: 560198, BD Pharmingen), Mouse Anti-Hamster IgG PE-conjugated Antibody (Catalog Number: F0120,R\&D system), Mouse Anti-human KDR (KDR-PE, FAB357P, R\&D) and Mouse Anti-Human NRP-1 (NRP-1-PE, Material Number: 565951, BD) antibodies were used at a ratio of 1:20. Single-cell suspensions were subsequently incubated with antibody or antibodies at $4^{\circ} \mathrm{C}$ for about 40 mins. Flow cytometric detection of the cell surface antigens were performed on a BD Accuri ${ }^{\mathrm{TM}}$ C6 Plus personal flow cytometer (Becton Dickinson). Compensation was set by single-positive controls. 
PSCs-derived ECs/EPCs were incubated with 10g/mL DiI-Ac-LDL (Molecular Probes) in serum-free EBM-2 (Lonza) for 4 hours at $37^{\circ} \mathrm{C}$, respectively.

\subsection{In vitro capillary network formation assay on Matrigel}

PSCs-derived ECs/EPCs were trypsinized and resuspended in EGM-2 media with 16\% FBS. Cells were plated at a density of $1.0 \times 10^{4}$ cells per well in triplicate in 96 -well plates coated with $50 \mu \mathrm{l}$ of growth factor - reduced Matrigel (BD Biosciences). Plates were incubated overnight at $37^{\circ}$ C. After 6 h of incubation, photomicrographs were taken from each well at 10x magnification using an Olympus CKX41 microscope with a 10x objective.

\subsection{Cell transplantation and therapy in Zebrafish}

Zebrafish, the transgenic line Tg (Flk: GFP) were maintained according to standard procedures in compliance with local approval. After 48 hours post fertilization (hpf), embryos were used to inject PSCs-derived ECs/EPCs stained with CM-Dil at approximately $60 \mu \mathrm{m}$ above the ventral end of the duct of Cuvier, then the embryos were maintained at $30^{\circ} \mathrm{C}$ for 48 hours. Fluorescent image acquisition was performed using a Leica MZ16FA stereo-microscope. Zebrafish embryos were treated with sugen5416 for 24 hours at $4 \mathrm{hpf}$, then 20-30 fish were respectively therapied by PSCs-derived ECs/EPCs /medium (EGM2 $+16 \% \mathrm{FBS})$ and maintained at $30^{\circ} \mathrm{C}$ for 48 hours, the number of normal zebrafish were recorded. The experiments were repeated three times. Euthanasia of all zebrafish was performed by exposure to bleach or rapid freezing followed by maceration.

\subsection{EPCs from adult peripheral blood samples}

EPCs were isolated from human peripheral blood (PB) which were obtained from six female donors, including three IPAH patients and three normal adults, aged between 25 and 40 
years. Fresh human PB (20mL) was obtained under full ethical approval; then mononuclear cells (MNCs) were isolated from PB by density gradient centrifugation and cultured in EGM2(Lonza) supplemented with 16\% FBS.

2.8 RNA extraction, cDNA synthesis and RT-qPCR

Total RNA from human cell lines was extracted with Trizol (Life Technologies). RNA yield was determined using the NanoDrop ND-1000 spectrophotometer (NanoDrop Technologies). Total RNA $(1 \mu \mathrm{g})$ was converted to cDNA using the PrimeScript ${ }^{\mathrm{TM}}$ RT reagent Kit with gDNA Eraser (TAKARA). Quantitative PCR (qPCR) was done using TransStart Tip Green qPCR SuperMix (TransGen Biotech) and detection was achieved using the CFX Connect ${ }^{\mathrm{TM}}$ Real-Time System (BIO-RAD). Primer sequence are listed in Supplementary Table 1. Expression of target genes was normalized to reference gene GAPDH.

\subsection{Microarray analysis}

Samples including IPAH-EPC1, IPAH-EPC2, IPAH-EPC3, normal EPCs (Con1, Con2, Con3) and PSCs-derived EPCs (H7EC, H9EC and 202EC) were used to do microarray analysis with HG-U133 Plus_2. Microarray data were carried out quality control, then normalized using rma method from R package affy. Differentially expressed genes (DEGs) were obtained by T test. DEGs (log FoldChange $<-2$ or $>2$, and $\mathrm{p}$-Value $<0.05$ ) were carried out gene ontology (GO) clustering analysis by R package clusterProfiler (Yu et al. 2012).

\subsection{Immunofluorescence assay}

PSCs-derived ECs/EPCs were fixed with 4\% (w/v) paraformaldehyde for $10 \mathrm{~min}$ and permeabilized with $0.1 \%(\mathrm{v} / \mathrm{v})$ Triton X-100 in PBS for 5 min. After blocking with 10\% (v/v) 
donkey serum (Solarbio, SL050) for 30 min, cells were incubated with primary following antibodies: anti-CD133 (ABclonal, 1155750301, 1:100) overnight at $4^{\circ}$ C. Cells were washed with PBS, then incubated with secondary antibodies conjugated with Alexa-488 (Molecular Probe) and visualized by confocal microscopy. The confocal images were obtained with a Zeiss confocal microscope. All the images were taken at room temperature and images were analyzed using a ZEN 2.6(blue edition).

\subsection{Statistical analysis}

Statistical analyses were performed using Student' s t-test and data were reported as mean \pm s.d. or standard error of the mean, Figure legends show the number of biological repeats for each experiment (n), the experiments were repeated three or more than three times. Statistical significance was assumed when $\mathrm{P}<0.05$.

\section{Results}

\subsection{Exploring the factors affecting PSCs-derived EC differentiation efficiency}

A few protocols for PSCs-derived ECs have been reported by others can generate about 20\% ECs (Zhang, Schwartz, et al. 2017). However, it is still not enough for cell therapy or other transplantation purpose. So we tried to identify the factors affecting endothelial cell differentiation and optimize the protocol according to recent published protocols (Duan et al. 2018; Patsch et al. 2015; Wang et al. 2018) to provide a schematic diagram (Fig. 1A). Firstly, we seeded approximately $3 \times 10^{4}$ cells/well in a 12-well plate instead of approximately $1 \times 10^{5}$ cells $/ \mathrm{cm}^{2}$ in previous studies. Secondly, we performed the differentiation with increasing cell number and found that the efficiency decreased with 
seeding cells number more than 10000 per well for H1 ESCs (Fig. 1B). Then, considering the high occurrence of PAH in females, we used H9-ESCs(female) for subsequent experiments. As an important mesoderm inducer, BMP4 was applied at an optimized concentration in our two-stage protocol (first stage and second stage). We also tested whether BMP4 affected PSCs-derived EC differentiation efficiency in the second stage and found that in the presence of BMP4 the $\mathrm{CD} 31^{+}$cells could be obtained about double the number than the combination without BMP4(Fig. 1C); BMP4 also promoted the generation of CD31 ${ }^{+} \mathrm{CD} 34^{+}$cells at the same level (Bai et al. 2010). With the increased concentration of SB431542 (5 $\mu \mathrm{M}, 10 \mu \mathrm{M}$ and $20 \mu \mathrm{M})$ in the second stage, the differentiation efficiency increased (Fig. 1D-E). Thirdly, mesoderm cells treated with Rock inhibitor were induced to differentiate into skeletal myocytes (Sadahiro et al. 2018), so we predicted that Y27632 plays the same role in the process of EC differentiation. In addition, we used Y27632 to improve cell survival after passage by treating 202-iPSCs with Y27632 for one day or three days and showed that the three-day induction resulted in a higher differentiation rate $(41.9 \% \pm 4.78 \%)$ than the one-day induction $(6.37 \% \pm 1.07 \%)$ (Fig. $1 \mathrm{~F}-\mathrm{G})$. From the results above, we concluded that the differentiation efficiency decreases with increasing seeding cell number (within 10,000-60,000), BMP4 and SB431542 promote PSCs-derived EC differentiation in the second stage, and Y27632 promotes hESC and iPSC differentiation towards ECs. However, not all lines have the same increase rate as these hPSCs, especially in patient derived iPSCs, in the next step we further examine the EC differentiation potential with some reagents.

Insert Fig. 1 
3.2 DMSO plays an important role in PSCS-derived hemogenic endothelial (HE) cell and PSCSderived vascular EC differentiation

The differentiation of two main ECs type - hemogenic endothelial (HE) cell and vascular endothelial (VC) cell from human PSCs were both examined. We carefully compared the solvents of the reagents used in the differentiation process and found that when using Y27632 dissolved in DMSO, the differentiation efficiency was high, but when Y27632 was dissolved in ddH2O, the differentiation efficiency was low. Therefore, we hypothesized that the addition of DMSO results in increased differentiation efficiency. Also we observed higher differentiation rate when we supplied medium with Y27632 dissolved in DMSO rather than in $\mathrm{H} 2 \mathrm{O}$ for one/three days (Fig. 2A-B). Furthermore, we obtained the same result in another chemically defined medium (CDM) (Supplementary Fig. 1). Therefore, DMSO is also an important reagent for PSCs-derived EC differentiation.

\section{Insert Fig. 2}

We also improved the hemogenic endothelial cell differentiation protocol by adding Y27632 and DMSO in a previous protocol (Wang et al. 2018). When we added Y27632 in water and DMSO $(1 \mu \mathrm{l} / \mathrm{mL})$ for the first three days, we found that there was a higher differentiation efficiency than adding only Y27632 at all stages for APLNR+ cells $(29.87 \% \pm 17.09 \%$ versus $5.3 \% \pm 0.1 \%), \quad C D 31{ }^{+}$CD $34^{+}$cells $(37.70 \% \pm 1.55 \%$ versus $2.39 \% \pm 0.17 \%)$, and $\mathrm{CD}_{4} 3^{+}$cells $(21.85 \% \pm 6.31 \%$ versus $9.17 \% \pm 0.65 \%)$ (Fig. $\left.2 \mathrm{C}-\mathrm{D}\right)$. We also confirmed that adding DMSO promotes HE cell differentiation. 


\subsection{A modified protocol for generating ECs from human PSCS}

Thus far, we have tested the factors affecting EC differentiation, including seeding cell number, induction time, BMP4, SB431542, Y27632 and DMSO to achieve best differentiation potential with H1 ESCs.

Then we seeded approximately 3 x 104 cells/well in a 12-well plate using $10 \mu \mathrm{M}$ Y27632 dissolved in DMSO and $10 \mathrm{ng} / \mathrm{mL}$ BMP4 for 3 days. After 7 days of differentiation, the cells were analysed directly using flow cytometry, which showed that H1 ESCs generated $92.17 \% \pm 0.42 \%$ endothelial cells (Fig. 3A-D). In the end, we were able to optimize a highly efficient differentiation system of PSCs-derived ECs.

\section{Insert Fig. 3}

\subsection{PSCS-derived ECS function as endothelial cells}

PSCs-derived ECs were isolated by using CD31+ MicroBeads and were cultured in EGM2 with 16\% FBS. To characterize the PSCs-derived ECs, we carried out two assays, a Dil-AcLDL uptake assay and a tube formation assay. As a result, we verified that PSCs-derived ECs had the ability to take up Dil-Ac-LDL (Fig. 4A) and form capillary-like structures after 4 hours or 12 hours of incubation on Matrigel (Fig. 4B). To further demonstrate that PSCsderived ECs have the ability to home to the vasculature of zebrafish in vivo (Orlova et al. 2014), we examined the engraftment potential of PSCs-derived ECs through the brief outline (Fig. 4C). When PSCs-derived ECs were injected into the vessels of 48 hpf zebrafish embryos, the cells were capable of integrating into the vascular system that had already developed (Fig. 4D). In addition, we performed cell therapy on zebrafish embryos with 
vasculature deficiency and less blood flowing through vessels after Sugen 5416 treatment. The results demonstrated that the percentage of zebrafish returning to normal was higher $(26.71 \pm 5.86 \%)$ with PSCs-derived ECs treatment than with medium treatment (12.06 $\pm 4.49 \%)$ (Fig. 4E). This finding suggested that the PSCs-derived ECs have potential for vascular repair.

\section{Insert Fig. 4}

\subsection{PSCS-derived ECS have characteristics of EPCS}

EPCs have two distinct EPC subtypes, early EPCs and late EPCs (also called endothelial colony-forming cells, ECFCs), which can be generated by the induction of ESCs/iPSCs; furthermore, high proliferation capacity of differentiated CD31+NRP1+ECFCs is positively correlated with the expression level of NRP1 (Prasain et al. 2014; Yoder et al. 2007). To determine whether PSCs-derived ECs bear the property of ECFCs, we compared the cell morphology of PSCs-derived ECs with that of peripheral blood-derived EPCs and found that they were both typical cobblestone EC-like cells (Fig. 5A). We further detected increased expression of the NRP1 gene in PSCs-derived ECs during differentiation (Fig. 5B), which is consistent with ECFCs (Prasain et al. 2014). In addition, we also detected higher expression of another early EPC marker gene, CD133 (PROM1) (Kanayasu-Toyoda et al. 2016), on day 7 by qRT-PCR (Fig. 5C). We also examined the expression levels of another two marker genes, EFNB2 for arterial endothelium and EPHB4 for vein endothelium, on day 7 by qRT-PCR. We found that 202-iPSC-ECs isolated on day 7 had a higher expression level of EFNB2 than EPHB4 (Fig. 5C). From the results demonstrated above, we reasoned 
that the PSCs-derived ECs have characteristics of EPCs and thought them as PSCs-derived EPCs.

Insert Fig. 5

3.6 Microarray and RNA-seq data further reveal the molecular characteristics and application potential of PSCS-derived EPCS

We next conducted bioinformatics analysis on datasets of PSCs-derived EPCs, normal EPCs, idiopathic pulmonary arterial hypertension (IPAH)-derived EPCs and GSE93511 (2D_MG_H1EC and 2D_MG_HUVEC) (Zhang, Schwartz, et al. 2017). First, we analysed in detail the expression patterns of key factors such as CD31 (PECAM1), CD146 (MCAM), vWF, CD43 (SPM), CD45 (PTPRC), CD133 (PROM1), KDR, NRP1, EFBN2, EPBH4 and CD34. The heatmaps showed that PROM1, SPN and PTPRC were not expressed in HUVECs, and had low expression in PSCs-derived EPCs, normal EPCs, IPAH-EPCs (Fig. 6A and 6B); moreover, EFNB2 also had higher expression in PSCs-derived EPCs than normal EPCs and IPAH-EPCs (Fig. 6B), with the positive control showing higher level in 2D-MG-H1EC than 2D_MG_HUVEC (Fig. 6A). These results further confirmed that the PSCs-derived EPCs had features of arterial EPCs.

Furthermore, we generated additional heatmaps of homing-related genes, such as CXCR4 (Yuan et al. 2018), IGF2/IGF2R, and CXCL12 (Zhuang et al. 2009; Xiaowei et al. 2013; Ferrari et al. 2011), and protein markers of mesenchymal stem cells, including CD73 (NT5E), CD44, CD90 (THY1), CD105 (ENG) (Caplan 2015; Jiang et al. 2019), and insulinlike growth factor - binding protein 3 (IGFBP3), which can improve vessel repair (Lofqvist 
et al. 2007; Chang et al. 2007). Heatmaps showed that IGF2, CXCL12 and CD9O (THY1) were not expressed in HUVECs (Fig. 6C) but had higher expression in PSCs-derived EPCs, normal EPCs, IPAH-EPCs and 2D-MG-H1EC (Fig. 6C-D). The rest of the genes had considerable expression levels in all cells, while we found that IGFBP3 had lower expression in IPAH-EPCs than in PSCs-derived EPCs and normal EPCs (Fig. 6C-D). In addition, Gene Ontology (GO) analysis revealed that the genes highly expressed in PSCsderived EPCs were related to the biological process of mesenchyme development, mesenchymal cell differentiation and mesenchyme morphogenesis (Fig. 7C). From the above, we think that PSCs-derived EPCs have the characteristics of mesenchymal stem cells for homing.

\section{Insert Fig. 6}

Next, we analysed the correlation between PSCs-derived EPCs and normal EPCs, and the results showed that the correlation was greater than 90\% (Fig. 7A). In the process of cell culture, we found that IPAH-EPCs proliferated faster than PSCs-derived EPCs, and PSCsderived EPCs grew slightly faster than normal EPCs (data not shown). From microarray data, we also found that the relative expression level of MKi67, a cell proliferation marker gene, was the highest in IPAH-EPCs, followed by PSCs-derived EPCs, and it was the lowest in normal EPCs (Fig. 7B). In view of the high similarity between PSCs-derived EPCs and normal EPCs, we performed Gene Ontology biological process (GOBP) analyses of PSCsderived EPCs and IPAH-EPCs relative to normal EPCs. Our results showed that all genes upregulated in IPAH-EPCs were enriched in the top 20 biological processes related to cell division, while some genes of PSCs-derived EPCs were clustered in biological processes 
related to cell division, extracellular matrix, differentiation and development (Fig. 7C-D). These data again showed that IPAH-EPCs had a higher proliferation rate, which was consistent with previous results. In addition, to better understand the molecular characteristics of PSCs-derived EPCs, we preformed further GOBP analyses of PSCsderived EPCs and normal EPCs relative to IPAH-EPCs. In the top 20 biological processes, our results showed that genes upregulated in PSCs-derived EPCs were enriched in immune-related biological processes, the top four of which are related to neutrophils (Fig. 7E); furthermore, some biological processes of normal EPCs were also related to immunity (Fig. 7F). This revealed that IPAH-EPCs had fewer immune-related molecular characteristics and enhanced proliferation capacity, suggesting that PSCs-derived EPCs maintained normal endothelial cell characteristics as well as function in therapy.

\section{Insert Fig. 7}

\section{Discussion}

Compared with other methods, such as EBs, coculture and monolayers, our optimized differentiation method is simplified and feasible for large-scale production. Although the differentiation efficiency of cells has been reported to be up to $48.43 \%-66.01 \%$ and 42.21\%-51.9\% by using coculture and EB methods respectively (Prasain et al. 2014), the process of differentiation is complex and time-consuming. The monolayer cell differentiation method is applied to derive endothelial cells because of its high efficiency and short cycle. For example, a small molecule differentiation approach shorten the process and induces more than 50\% hPSCs into CD34+CD31+ cells in 19-9-11 iPSCs in 5 
days (Lian et al. 2014); after 5 days of differentiation, H1 ESCs generate $74 \% \pm 2 \%$ endothelial cells(Zhang, Schwartz, et al. 2017); then, the authors developed a "five factor" differentiation system (consisting of FGF2, VEGFA, SB431542, RESV, and L690) with which the maximum differentiation efficiency of endothelial cells reached 96.5\% in 6 days (Zhang, Chu, et al. 2017). However, some specific conditions of endothelial differentiation still need to be optimized; for example, in a long-term process of endothelial cell differentiation, we could not achieve the same differentiation efficiency with a cell density of $1 \times 10^{5}$ cells $/ \mathrm{cm}^{2}$ (Zhang, Schwartz, et al. 2017). In addition, to obtain maximum differentiation efficiency, the conditions must be as consistent as possible in the differentiation system. The cell status, especially at the seeding stage, had a fundamental impact on the final efficiency. For example, using embryonic stem cells that have already differentiated greatly reduces the outcome production of ECs.

In addition, DMSO impacts PSCs-derived EPC differentiation during the whole process, which we previously ignored because it was only deemed as solvent to dissolve the chemicals. In our study, we used two chemical molecules, Y27632 and SB431542, although others have used CHIR99021 to promote EC differentiation (Nguyen et al. 2016; Zhang, Schwartz, et al. 2017). According to our experience, DMSO-treated cells need to be kept in a separate $37^{\circ} \mathrm{C}$ and 5\% CO2 incubator, which could avoid inducing the differentiation of other cultured cells, suggesting that DMSO could affect cell differentiation and should be used with care. To better understand the function of DMSO, we searched papers referring to ESC differentiation, and found some reported that the efficiency of hPSC differentiation is improved even if hPSCs are treated with DMSO for a 
short time (Li et al. 2018); the addition of DMSO also downregulates the expression of stemness-related genes such as OCT4 and NANOG and increases the proficiency of hepatic differentiation (Czysz, Minger, and Thomas 2015); DMSO at 0.01\% and 0.1\% concentrations can act as an induction agent for the formation of mesodermal phenotypes (Pal et al. 2012). These findings show that DMSO acts as a differentiation inducer in mesoderm differentiation.

The role of the inhibitor Y27632 in the process of PSCs-derived EC and HE differentiation has also been neglected because robust differentiation protocols started with single cells by using Y27632 at seeding to promote cell survival. This inhibitor can phosphorylate and activate the myosin II pathway and inhibit the E-cadherin-dependent apoptotic pathway (Vernardis et al. 2017). Some studies have reported that Y27632 enhances the differentiation of human term placenta-derived trophoblasts in vitro (Motomura et al. 2017), differentiation induction (Kurosawa 2012) and mesendodermal differentiation (Maldonado et al. 2016). In addition, the extension of treatment time to 3 days in the first stage of mesoderm induction may be able to substantially promote mesodermal cell production, consistent with another study (Nguyen et al. 2016).

PSCs-derived EPCs have special molecular characteristics and can be thought as a new EC-like subpopulation. Haematopoietic and endothelial progenitor cells share a number of cell-surface markers because they may originate from a common precursor, the haemangioblast (Ingram et al. 2004). It has been reported that CD34+ CD133+ VEGFR2+ cells are haematopoietic and may not actually be true EPCs (Medina et al. 2010), so we chose the endothelial marker $\mathrm{CD} 31^{+}$rather than $\mathrm{CD} 34^{+} \mathrm{CD} 133^{+}$VEGFR2 ${ }^{+}$to isolate PSCs- 
derived EPCs and then found their cell morphology as same as that of blood-derived normal EPCs; moreover, the expansion ability of PSCs-derived EPCs was similar with that of blood-derived normal EPCs, and they were both less proliferative than EPCs from IPAH patients. Finally, gene expression analysis from our microarray data showed that PSCsderived EPCs expressing CD40,CD90 and CD105 were similar to mesenchymal stem cells, and the zebrafish transplantation experiment proved their function in vascular repairment; moreover, genes highly expressed in PSCs-derived EPCs were found to be involved in the biological processes of heart morphogenesis, cardiac chamber morphogenesis, cardiac septum morphogenesis, cardiac ventricle development and cardiac chamber development (Fig. 7C), which indicates that PSCs-derived EPCs have potential application value.

In the process of cell culture, we found that the cell morphology of IPAH-EPCs were not different from those of normal EPCs (Fig. 5A), but the proliferation ability of IPAH-EPCs was higher than that of normal EPCs, which is obvious in cell culture. Then, we analysed the expression levels of CD31, KDR, NRP1 and CD34 by flow cytometry and found that the percentage of $\mathrm{NRP}^{+}$cells was higher in IPAH-EPCs and PSCs-derived EPCs (Supplementary Fig. 2). Microarray analysis showed that the expression of the IGFBP3 gene in IPAH-EPCs was significantly lower than that in normal EPCs and PSCs-derived EPCs (Fig. 6D). Moreover, GO clustering analysis revealed that IPAH-EPCs had high proliferative capacity and defects in immune-related gene expression (Fig. 7D and F), which could be further studied.

What is worth to mention is that we need focus on the most specific endothelial marker VE-cadherin (CDH5/CD144) used to isolate endothelial cells in other articles (Patsch et al. 
2015; Gu et al. 2017). We also checked the expression level of VE-cadherin, and found that VE-cadherin has a higher expression level on day 5 than on day 7 in our optimized protocol by qRT-PCR (Supplementary Fig. 3A); in addition, another article reported that CD31 and VE-cadherin have the similar expression tendency in the process of EC differentiation (Nguyen et al. 2016), so we chose to follow the original protocol with CD31 and CD34 (Zhang, Schwartz, et al. 2017). At last, we found that VE-cadherin expressed highly through microarray analysis (Supplementary Table 2), detected high expression of CD133 through immunofluorescence assay (Supplementary Fig. 3B) in isolated CD31 ${ }^{+}$cells which can form colonies (Supplementary Fig. 3C). These evidences confirmed that isolated CD31+ cells were PSCs-derived EPCs.

Moreover, the components in our EC differentiation system is compatible with other CDM medium. To verify the system and reduce the cost, we tested another CDM formulation and repeated the protocol with high differentiation efficiency as well. On the one hand, the function of each factor in the differentiation process was re-evaluated; on the other hand, this study lays a foundation for future application. PSCs-derived EPCs may be a new subpopulation have characteristics of early EPCs and mesenchymal stem cells for homing and possess greater cell therapeutic potential. Finally, we demonstrated that IPAH-EPCs had higher proliferation ability than normal EPCs.

\section{Authors' contributions}

K.Z. Q. and J.Y. participated in the research design, conducted the experiments, performed the data analysis and wrote the manuscript. All authors reviewed, 
revised the final version and approved manuscript submission.

\section{Compliance with Ethical Standards}

\section{Conflict of Interest}

The authors declare that they have no competing interests.

\section{Ethics approval and consent to participate}

All experiments were performed in accordance with the principles of the China Zebrafish Resource Center and approved by the Research Ethics Committee of Peking Union Medical College. All animal procedures were carried out in the Zebrafish Laboratory of State Key Laboratory of Medical Molecular Biology, Institute of Basic Medical Sciences, Chinese Academy of Medical Sciences and Peking Union Medical College. All experimental studies using human samples comply with the Declaration of Helsinki and were approved by the local ethics committee (Institute of Basic Medical Sciences, Chinese Academy of Medical Sciences and Peking Union Medical College). All persons gave informed consent before the study.

\section{Consent for publication}

Not applicable.

\section{Acknowledgements}

This research was supported by Grants from National Key Research and Development 
Program of China-stem cell and translational research (No: 2016YFA0102300), CAMS Innovation Fund for Medical Sciences (CIFMS 2016-I2M-4-003), China National

Thousand (Young) Talents Program of Jun Yang. The authors thank Hongtao Wang and Mengge Wang from State Key Laboratory of Experimental Hematology, Institute of Hematology \& Blood Diseases Hospital, Tianjin 300020, China for their guidance with Hemogenic Endothelial (HE) differentiation.

\section{References}

Bai, H., Gao, Y., Arzigian, M., Wojchowski, D.M., Wu, W.S., Wang, Z.Z., 2010. BMP4 regulates vascular progenitor development in human embryonic stem cells through a Smaddependent pathway. J Cell Biochem 109, 363-374. https://doi.org/10.1002/jcb.22410

Belair, D.G., Whisler, J.A., Valdez, J., Velazquez, J., Molenda, J.A., Vickerman, V., Lewis, R., Daigh, C., Hansen, T.D., Mann, D.A., Thomson, J.A., Griffith, L.G., Kamm, R.D., Schwartz, M.P., Murphy, W.L., 2015. Human vascular tissue models formed from human induced pluripotent stem cell derived endothelial cells. Stem Cell Rev Rep 11, 511-525. https://doi.org/10.1007/s12015-014-9549-5

Caplan, A.I., 2015. Adult mesenchymal stem cells and women's health. Menopause 22, 131-135. https://doi.org/10.1097/GME.0000000000000408

Chang, K.H., Chan-Ling, T., McFarland, E.L., Afzal, A., Pan, H., Baxter, L.C., Shaw, L.C., Caballero, S., Sengupta, N., Li Calzi, S., Sullivan, S.M., Grant, M.B., 2007. IGF binding protein-3 regulates hematopoietic stem cell and endothelial precursor cell function during vascular development. Proc Natl Acad Sci U S A 104, 10595-10600. https://doi.org/10.1073/pnas.0702072104

Czysz, K., Minger, S., Thomas, N., 2015. DMSO efficiently down regulates pluripotency genes in human embryonic stem cells during definitive endoderm derivation and increases the proficiency of hepatic differentiation. PLoS One 10, e0117689. https://doi.org/10.1371/journal.pone.0117689

Duan, F., Huang, R., Zhang, F., Zhu, Y., Wang, L., Chen, X., Bai, L., Guo, W., Chang, S.C., Hu, X., Na, J., 2018. Biphasic modulation of insulin signaling enables highly efficient hematopoietic differentiation from human pluripotent stem cells. Stem Cell Res Ther 9, 205. https://doi.org/10.1186/s13287-018-0934-x

Ferrari, D., Gulinelli, S., Salvestrini, V., Lucchetti, G., Zini, R., Manfredini, R., Caione, L., Piacibello, W., Ciciarello, M., Rossi, L., Idzko, M., Ferrari, S., Di Virgilio, F., Lemoli, R.M., 2011. Purinergic stimulation of human mesenchymal stem cells potentiates their chemotactic response to CXCL12 and increases the homing capacity and production of proinflammatory cytokines. Exp Hematol 39, 360-74, 374 e1-5. https://doi.org/10.1016/j.exphem.2010.12.001 
Foris, V., Kovacs, G., Marsh, L.M., Balint, Z., Totsch, M., Avian, A., Douschan, P., Ghanim, B., Klepetko, W., Olschewski, A., Olschewski, H., 2016. CD133+ cells in pulmonary arterial hypertension. Eur Respir J 48, 459-469. https://doi.org/10.1183/13993003.01523-2015

Gomberg-Maitland, M., Bull, T.M., Saggar, R., Barst, R.J., Elgazayerly, A., Fleming, T.R., Grimminger, F., Rainisio, M., Stewart, D.J., Stockbridge, N., Ventura, C., Ghofrani, A.H., Rubin, L.J., 2013. New trial designs and potential therapies for pulmonary artery hypertension. J Am Coll Cardiol 62, D82-91. https://doi.org/10.1016/j.jacc.2013.10.026

Gu, M., Shao, N.Y., Sa, S., Li, D., Termglinchan, V., Ameen, M., Karakikes, I., Sosa, G., Grubert, F., Lee, J., Cao, A., Taylor, S., Ma, Y., Zhao, Z., Chappell, J., Hamid, R., Austin, E.D., Gold, J.D., Wu, J.C., Snyder, M.P., Rabinovitch, M., 2017. Patient-Specific iPSC-Derived Endothelial Cells Uncover Pathways that Protect against Pulmonary Hypertension in BMPR2 Mutation Carriers. Cell Stem Cell 20, 490-504 e5. https://doi.org/10.1016/j.stem.2016.08.019

Han, X., Chen, H., Huang, D., Chen, H., Fei, L., Cheng, C., Huang, H., Yuan, G.C., Guo, G., 2018. Mapping human pluripotent stem cell differentiation pathways using high throughput single-cell RNA-sequencing. Genome Biol 19, 47. https://doi.org/10.1186/s13059-0181426-0

Ingram, D.A., Mead, L.E., Tanaka, H., Meade, V., Fenoglio, A., Mortell, K., Pollok, K., Ferkowicz, M.J., Gilley, D., Yoder, M.C., 2004. Identification of a novel hierarchy of endothelial progenitor cells using human peripheral and umbilical cord blood. Blood 104, 2752-2760. https://doi.org/10.1182/blood-2004-04-1396

James, D., Nam, H.-S., Seandel, M., Nolan, D., Janovitz, T., Tomishima, M., Studer, L., Lee, G., Lyden, D., Benezra, R., Zaninovic, N., Rosenwaks, Z., Rabbany, S.Y., Rafii, S., 2010. Expansion and maintenance of human embryonic stem cell-derived endothelial cells by TGF beta inhibition is Id1 dependent. Nat. Biotechnol. 28, 161-U15. https://doi.org/10.1038/nbt1605

Jiang, B., Yan, L., Wang, X., Li, E., Murphy, K., Vaccaro, K., Li, Y., Xu, R.H., 2019. Concise Review: Mesenchymal Stem Cells Derived from Human Pluripotent Cells, an Unlimited and Quality-Controllable Source for Therapeutic Applications. Stem Cells 37, 572-581. https://doi.org/10.1002/stem.2964

Jung, K.-H., Roh, J.-K., 2008. Circulating Endothelial Progenitor Cells in Cerebrovascular Disease. J. Clin. Neurol. 4, 139-147. https://doi.org/10.3988/jcn.2008.4.4.139

Kanayasu-Toyoda, T., Tanaka, T., Kikuchi, Y., Uchida, E., Matsuyama, A., Yamaguchi, T., 2016. CellSurface MMP-9 Protein Is a Novel Functional Marker to Identify and Separate Proangiogenic Cells from Early Endothelial Progenitor Cells Derived from CD133(+) Cells. Stem Cells 34, 1251-1262. https://doi.org/10.1002/stem.2300

Kurosawa, H., 2012. Application of Rho-associated protein kinase (ROCK) inhibitor to human pluripotent stem cells. J Biosci Bioeng 114, 577-581. https://doi.org/10.1016/j.jbiosc.2012.07.013

Li, J., Narayanan, C., Bian, J., Sambo, D., Brickler, T., Zhang, W., Chetty, S., 2018. A transient DMSO treatment increases the differentiation potential of human pluripotent stem cells through the Rb family. PLoS One 13, e0208110. https://doi.org/10.1371/journal.pone.0208110

Lian, X., Bao, X., Al-Ahmad, A., Liu, J., Wu, Y., Dong, W., Dunn, K.K., Shusta, E. V, Palecek, S.P., 2014. Efficient differentiation of human pluripotent stem cells to endothelial progenitors via small-molecule activation of WNT signaling. Stem Cell Reports 3, 804-816. 
https://doi.org/10.1016/j.stemcr.2014.09.005

Lofqvist, C., Chen, J., Connor, K.M., Smith, A.C., Aderman, C.M., Liu, N., Pintar, J.E., Ludwig, T., Hellstrom, A., Smith, L.E., 2007. IGFBP3 suppresses retinopathy through suppression of oxygen-induced vessel loss and promotion of vascular regrowth. Proc Natl Acad Sci U S A 104, 10589-10594. https://doi.org/10.1073/pnas.0702031104

Maldonado, M., Luu, R.J., Ramos, M.E., Nam, J., 2016. ROCK inhibitor primes human induced pluripotent stem cells to selectively differentiate towards mesendodermal lineage via epithelial-mesenchymal transition-like modulation. Stem Cell Res 17, 222-227. https://doi.org/10.1016/j.scr.2016.07.009

Medina, R.J., O'Neill, C.L., O'Doherty, T.M., Wilson, S.E., Stitt, A.W., 2012. Endothelial progenitors as tools to study vascular disease. Stem Cells Int 2012, 346735. https://doi.org/10.1155/2012/346735

Medina, R.J., O'Neill, C.L., Sweeney, M., Guduric-Fuchs, J., Gardiner, T.A., Simpson, D.A., Stitt, A.W., 2010. Molecular analysis of endothelial progenitor cell (EPC) subtypes reveals two distinct cell populations with different identities. BMC Med Genomics 3, 18. https://doi.org/10.1186/1755-8794-3-18

Motomura, K., Okada, N., Morita, H., Hara, M., Tamari, M., Orimo, K., Matsuda, G., Imadome, K.I., Matsuda, A., Nagamatsu, T., Fujieda, M., Sago, H., Saito, H., Matsumoto, K., 2017. A Rhoassociated coiled-coil containing kinases (ROCK) inhibitor, Y-27632, enhances adhesion, viability and differentiation of human term placenta-derived trophoblasts in vitro. PLoS One 12, e0177994. https://doi.org/10.1371/journal.pone.0177994

Nguyen, M.T.X., Okina, E., Chai, X., Tan, K.H., Hovatta, O., Ghosh, S., Tryggvason, K., 2016. Differentiation of Human Embryonic Stem Cells to Endothelial Progenitor Cells on Laminins in Defined and Xeno-free Systems. Stem Cell Reports 7, 802-816. https://doi.org/10.1016/j.stemcr.2016.08.017

Niskanen, H., Tuszynska, I., Zaborowski, R., Heinaniemi, M., Yla-Herttuala, S., Wilczynski, B., Kaikkonen, M.U., 2018. Endothelial cell differentiation is encompassed by changes in long range interactions between inactive chromatin regions. Nucleic Acids Res 46, 1724-1740. https://doi.org/10.1093/nar/gkx1214

Orlova, V. V, van den Hil, F.E., Petrus-Reurer, S., Drabsch, Y., ten Dijke, P., Mummery, C.L., 2014. Generation, expansion and functional analysis of endothelial cells and pericytes derived from human pluripotent stem cells. Nat. Protoc. 9, 1514-1531. https://doi.org/10.1038/nprot.2014.102

Ormiston, M.L., Toshner, M.R., Kiskin, F.N., Huang, C.J., Groves, E., Morrell, N.W., Rana, A.A., 2015. Generation and Culture of Blood Outgrowth Endothelial Cells from Human Peripheral Blood. J Vis Exp e53384. https://doi.org/10.3791/53384

Pal, R., Mamidi, M.K., Das, A.K., Bhonde, R., 2012. Diverse effects of dimethyl sulfoxide (DMSO) on the differentiation potential of human embryonic stem cells. Arch Toxicol 86, 651-661. https://doi.org/10.1007/s00204-011-0782-2

Park, S.J., Lee, J.H., Lee, S.G., Lee, J.E., Seo, J., Choi, J.J., Jung, T.H., Chung, E.B., Kim, H.N., Ju, J., Song, Y.H., Chung, H.M., Lee, D.R., Moon, S.H., 2019. Functional Equivalency in Human Somatic Cell Nuclear Transfer-Derived Endothelial Cells. Stem Cells 37, 623-630. https://doi.org/10.1002/stem.2986

Park, T.S., Bhutto, I., Zimmerlin, L., Huo, J.S., Nagaria, P., Miller, D., Rufaihah, A.J., Talbot, C., Aguilar, 
J., Grebe, R., Merges, C., Reijo-Pera, R., Feldman, R.A., Rassool, F., Cooke, J., Lutty, G., Zambidis, E.T., 2014. Vascular progenitors from cord blood-derived induced pluripotent stem cells possess augmented capacity for regenerating ischemic retinal vasculature. Circulation 129, 359-372. https://doi.org/10.1161/CIRCULATIONAHA.113.003000

Patsch, C., Challet-Meylan, L., Thoma, E.C., Urich, E., Heckel, T., O'Sullivan, J.F., Grainger, S.J., Kapp, F.G., Sun, L., Christensen, K., Xia, Y., Florido, M.H., He, W., Pan, W., Prummer, M., Warren, C.R., Jakob-Roetne, R., Certa, U., Jagasia, R., Freskgard, P.O., Adatto, I., Kling, D., Huang, P., Zon, L.I., Chaikof, E.L., Gerszten, R.E., Graf, M., Iacone, R., Cowan, C.A., 2015. Generation of vascular endothelial and smooth muscle cells from human pluripotent stem cells. Nat Cell Biol 17, 994-1003. https://doi.org/10.1038/ncb3205

Prasain, N., Lee, M.R., Vemula, S., Meador, J.L., Yoshimoto, M., Ferkowicz, M.J., Fett, A., Gupta, M., Rapp, B.M., Saadatzadeh, M.R., Ginsberg, M., Elemento, O., Lee, Y., Voytik-Harbin, S.L., Chung, H.M., Hong, K.S., Reid, E., O'Neill, C.L., Medina, R.J., Stitt, A.W., Murphy, M.P., Rafii, S., Broxmeyer, H.E., Yoder, M.C., 2014. Differentiation of human pluripotent stem cells to cells similar to cord-blood endothelial colony-forming cells. Nat Biotechnol 32, 11511157. https://doi.org/10.1038/nbt.3048

Sadahiro, T., Isomi, M., Muraoka, N., Kojima, H., Haginiwa, S., Kurotsu, S., Tamura, F., Tani, H., Tohyama, S., Fujita, J., Miyoshi, H., Kawamura, Y., Goshima, N., Iwasaki, Y.W., Murano, K., Saito, K., Oda, M., Andersen, P., Kwon, C., Uosaki, H., Nishizono, H., Fukuda, K., leda, M., 2018. Tbx6 Induces Nascent Mesoderm from Pluripotent Stem Cells and Temporally Controls Cardiac versus Somite Lineage Diversification. Cell Stem Cell 23, 382-395 e5. https://doi.org/10.1016/j.stem.2018.07.001

Sekiguchi, H., II, M., Losordo, D.W., 2009. The Relative Potency and Safety of Endothelial Progenitor Cells and Unselected Mononuclear Cells for Recovery from Myocardial Infarction and Ischemia. J. Cell. Physiol. 219, 235-242. https://doi.org/10.1002/jcp.21672

Toshner, M., Voswinckel, R., Southwood, M., Al-Lamki, R., Howard, L.S., Marchesan, D., Yang, J., Suntharalingam, J., Soon, E., Exley, A., Stewart, S., Hecker, M., Zhu, Z., Gehling, U., Seeger, W., Pepke-Zaba, J., Morrell, N.W., 2009. Evidence of dysfunction of endothelial progenitors in pulmonary arterial hypertension. Am J Respir Crit Care Med 180, 780-787. https://doi.org/10.1164/rccm.200810-16620C

Vernardis, S.I., Terzoudis, K., Panoskaltsis, N., Mantalaris, A., 2017. Human embryonic and induced pluripotent stem cells maintain phenotype but alter their metabolism after exposure to ROCK inhibitor. Sci Rep 7, 42138. https://doi.org/10.1038/srep42138

Wang, H., Liu, C., Liu, X., Wang, M., Wu, D., Gao, J., Su, P., Nakahata, T., Zhou, W., Xu, Y., Shi, L., Ma, F., Zhou, J., 2018. MEIS1 Regulates Hemogenic Endothelial Generation, Megakaryopoiesis, and Thrombopoiesis in Human Pluripotent Stem Cells by Targeting TAL1 and FLI1. Stem Cell Reports 10, 447-460. https://doi.org/10.1016/j.stemcr.2017.12.017

Ward, M.R., Stewart, D.J., Kutryk, M.J.B., 2007. Endothelial progenitor cell therapy for the treatment of coronary disease, acute $\mathrm{MI}$, and pulmonary arterial hypertension: Current perspectives. Catheter. Cardiovasc. Interv. 70, 983-998. https://doi.org/10.1002/ccd.21302

Xiaowei, C., Jia, M., Xiaowei, W., Yina, Z., 2013. Overexpression of CXCL12 chemokine up-regulates connexin and integrin expression in mesenchymal stem cells through PI3K/Akt pathway. Cell Commun Adhes 20, 67-72. https://doi.org/10.3109/15419061.2013.791682

Yoder, M.C., Mead, L.E., Prater, D., Krier, T.R., Mroueh, K.N., Li, F., Krasich, R., Temm, C.J., Prchal, 
J.T., Ingram, D.A., 2007. Redefining endothelial progenitor cells via clonal analysis and hematopoietic stem/progenitor cell principals. Blood 109, 1801-1809. https://doi.org/10.1182/blood-2006-08-043471

Yu, G., Wang, L.G., Han, Y., He, Q.Y., 2012. clusterProfiler: an R package for comparing biological themes among gene clusters. OMICS 16, 284-287. https://doi.org/10.1089/omi.2011.0118

Yuan, Z., Kang, L., Wang, Z., Chen, A., Zhao, Q., Li, H., 2018. 17beta-estradiol promotes recovery after myocardial infarction by enhancing homing and angiogenic capacity of bone marrow-derived endothelial progenitor cells through ERalpha-SDF-1/CXCR4 crosstalking. Acta Biochim Biophys Sin 50, 1247-1256. https://doi.org/10.1093/abbs/gmy127

Zhang, J., Chu, L.F., Hou, Z., Schwartz, M.P., Hacker, T., Vickerman, V., Swanson, S., Leng, N., Nguyen, B.K., Elwell, A., Bolin, J., Brown, M.E., Stewart, R., Burlingham, W.J., Murphy, W.L., Thomson, J.A., 2017. Functional characterization of human pluripotent stem cell-derived arterial endothelial cells. Proc Natl Acad Sci U S A 114, E6072-E6078. https://doi.org/10.1073/pnas.1702295114

Zhang, J., Schwartz, M.P., Hou, Z., Bai, Y., Ardalani, H., Swanson, S., Steill, J., Ruotti, V., Elwell, A., Nguyen, B.K., Bolin, J., Stewart, R., Thomson, J.A., Murphy, W.L., 2017. A Genome-wide Analysis of Human Pluripotent Stem Cell-Derived Endothelial Cells in 2D or 3D Culture. Stem Cell Reports 8, 907-918. https://doi.org/10.1016/j.stemcr.2017.02.014

Zhao, W., Zhao, L., Liao, J., Luo, Y., He, L., 2019. Early risk assessment of circulating endothelial progenitor cells and plasma stromal cell-derived factor-1 for nondisabling ischemic cerebrovascular events. BMC Neurol 19, 22. https://doi.org/10.1186/s12883-019-1250-5

Zhuang, Y., Chen, X., Xu, M., Zhang, L.Y., Xiang, F., 2009. Chemokine stromal cell-derived factor 1/CXCL12 increases homing of mesenchymal stem cells to injured myocardium and neovascularization following myocardial infarction. Chin Med J 122, 183-187.

\section{Figure legends}

Fig. 1 Identifying factors for PSCs-derived EPCs. (A) A schematic diagram of inducing human PSCs-derived ECs. (B) Number of seeding cells affects PSCs-derived EC differentiation efficiency as analysed by flow cytometry. (C) In the second step of PSCs-derived EC differentiation, adding BMP4 promotes PSCs-derived EC differentiation efficiency as analysed by flow cytometry. (D) and (E) In the second step of EC differentiation, appropriately increasing SB431542 promotes PSCs-derived EC differentiation efficiency as analysed by flow cytometry.

(F) and (G) The inhibitor Y27632 improves PSCs-derived EC differentiation efficiency as 
analysed by flow cytometry in the first step of 202-iPSC-EC differentiation when Y27632 was used for three days. Statistics of $\mathrm{CD} 31^{+} \mathrm{CD} 34^{+}$cells, $\mathrm{CD} 31^{+}$cells, $\mathrm{CD} 34^{+}$cells and $\mathrm{CD} 43^{+}$cells. Data are represented as the mean $\pm S D$. $n=3-4$, the experiments were repeated more than three independent times. Student's t test was performed $(* p<0.05, * \star p<0.01, * \star \star p<0.001)$.

Fig. 2 Adding DMSO improves EC and HE cell differentiation efficiency. (A) and (B) PSCsderived EC (H1EC) differentiation efficiency increases when the cells are treated with DMSO in the first step for one day or three days. Statistics of $\mathrm{CD} 31^{+} \mathrm{CD} 34^{+}$cells, $\mathrm{CD} 31^{+}$cells, $\mathrm{CD} 34^{+}$ cells and $C D 43^{+}$cells as analysed by flow cytometry. (C) and (D) Improved protocol for the HE differentiation of PSCs. A schematic digram of the stepwise induction process is shown, and DMSO treatment for three days in the first step promotes the differentiation efficiency as analysed by flow cytometry. Statistics of $\mathrm{APLNR}^{+}$cells, $\mathrm{CD} 31^{+} \mathrm{CD} 34^{+}$cells, $\mathrm{CD} 31^{+}$cells, $\mathrm{CD} 34^{+}$ cells and $C D 43^{+}$cells. Data are represented as the mean $\pm S D, n=3-4$, and the experiments were repeated more than three times. Student's t test was performed (ns: not significant, $\star \star p$ $<0.01, \quad * \star \star \star p<0.0001)$.

Fig. 3 Improved protocol for the highly efficient differentiation rate of PSCs-derived ECs. (A) schematic diagram of inducing human PSCs-derived ECs via a mesoderm intermediate. (B) Representative yields of APLNR+ cells as analysed by flow cytometry. (C) Representative yields of $\mathrm{CD}_{34^{+}} \mathrm{CD} 31^{+}$cells and $\mathrm{CD} 43^{+}$cells as analysed by flow cytometry after 7 days of differentiation. (D) Statistics of $\mathrm{CD} 31^{+} \mathrm{CD} 34^{+}$and $\mathrm{CD} 43^{+}$cells. Data are represented as the mean $\pm S D, n=3$, and the experiments were repeated three independent times. 
Fig. 4 PSCs-derived ECs have functional characteristics of endothelial cells. (A) Uptake assay of Dil-acetylated LDL (scale bars: $50 \mu \mathrm{m}$ ). (B) Tube formation assay of H1-derived ECs after 4 hours and 12 hours (scale bars: $500 \mu \mathrm{m}$ ). (C) Brief outline of Zebrafish experiments. (D) Vascular competence of PSCs-derived ECs in a zebrafish xenograft model. Representative image of ECs-derived vessel-type structures (in red) within embryonic zebrafish (Flk: GFP; in green) 2 days after implantation, with magnification of the vessel. Scale bars are $300 \mu \mathrm{m}$. (E) Using a zebrafish model for gene therapy. Data are represented as the mean $\pm S D, n=3$, and the experiments were repeated three times with 20-30 fish per condition. Student's t test was performed $(* p<0.05)$.

Fig. 5 PSCs-derived ECs have characteristics of EPCs. (A) Comparison of the cell morphology of PSCs-derived ECs (H7EC, 202EC) with peripheral blood-derived normal EPCs (normal EPC1, normal EPC2) and IPAH-EPCs (IPAH EPC1, IPAH EPC2) (scale bars: $50 \mu \mathrm{m}$ ). (B) qRT-PCR of NRP1, which was reported to promote ECFC proliferation. GAPDH was used as an internal control. (C) ECs from DAY 5 or DAY 7 were analysed by the expression of the genes CD133, EFNB2, and EPHB4. GAPDH was used as an internal control. Data are represented as the mean $\pm \mathrm{SD}, \mathrm{n}=3$, and the experiments were repeated three times. Student's t test was performed (* $p<0.05, * * p<0.01, * * * p<0.001)$

Fig. 6 Bioinformatics analysis further reveals the characteristics of PSCs-derived EPCs. (A) and (B) Heatmap of EC-related genes from the 2D_MG_H1EC and 2D_MG_HUVEC datasets from 
GSE93511 and our microarray data in IPAH-EPCs (IPAH1, IPAH2, IPAH3), normal EPCs (Con1, Con2, Con3) and PSCs-derived EPCs (H7EC, H9EC, 202EC). PROM1, SPN and PTPRC were not expressed, and EFNB2 had a higher expression level in HUVECs (A), but PROM1, SPN and PTPRC were highly expressed in PSCs-derived EPCs, normal EPCs, IPAH-EPCs and 2D-MGH1EC (B). Moreover, EFNB2 also had a higher expression level in PSCs-derived EPCs than in normal EPCs and IPAH-EPCs (B). (C) and (D) Heatmap of homing-related genes from the 2D_MG_H1EC and 2D_MG_HUVEC datasets from GSE93511 and our microarray data in IPAHEPCs (IPAH1, IPAH2, IPAH3), normal EPCs (Con1, Con2, Con3) and PSCs-derived EPCs (H7EC, H9EC, 202EC). IGF2, CXCL12 and CD90 (THY1) were not expressed in HUVECs (C), but had higher expression levels in PSCs-derived EPCs, normal EPCs, IPAH-EPCs (D) and 2D-MGH1EC (C). IGFBP3 had a lower expression level in IPAH-EPCs than in PSCs-derived EPCs and normal EPCs (D).

Fig. 7 PSCs-derived EPCs have special molecular characteristics compared with normal EPCs and IPAH-EPCs (IPAH1, IPAH2 and IPAH3) based on our microarray data. (A) Correlation analysis between normal EPCs (Con1, Con2, Con3) and PSCs-derived EPCs (H7EC, H9EC, 202EC). (B) MKi67 relative expression from microarray data. Data are represented as the mean \pm SD. $n=3$, Student's t test was performed $(* p<0.05)$. (C) and (D) GOBP analysis (TOP20) of PSCs-derived EPCs and IPAH-EPCs relative to normal EPCs. (E) and (F) GOBP analysis (TOP20) of PSCs-derived EPCs and normal EPCs relative to IPAH-EPCs. 
$A$

hESC

APLNR+cell

DO

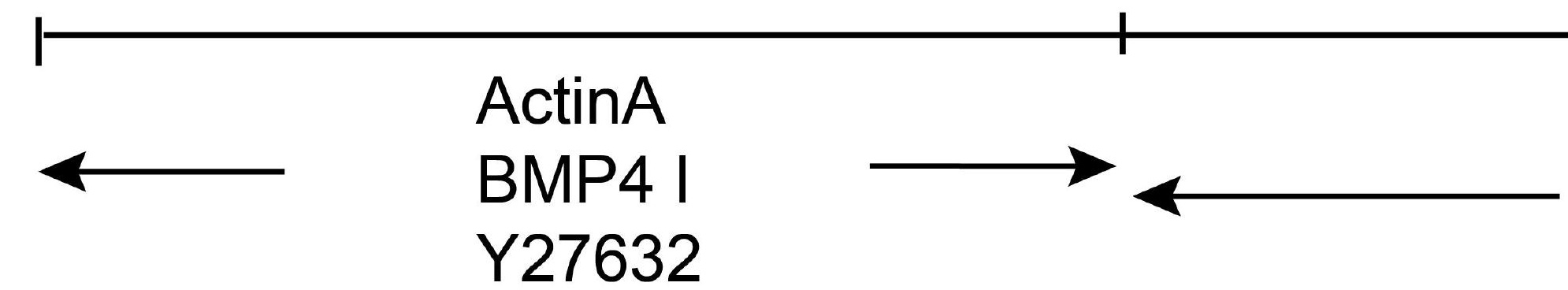

B

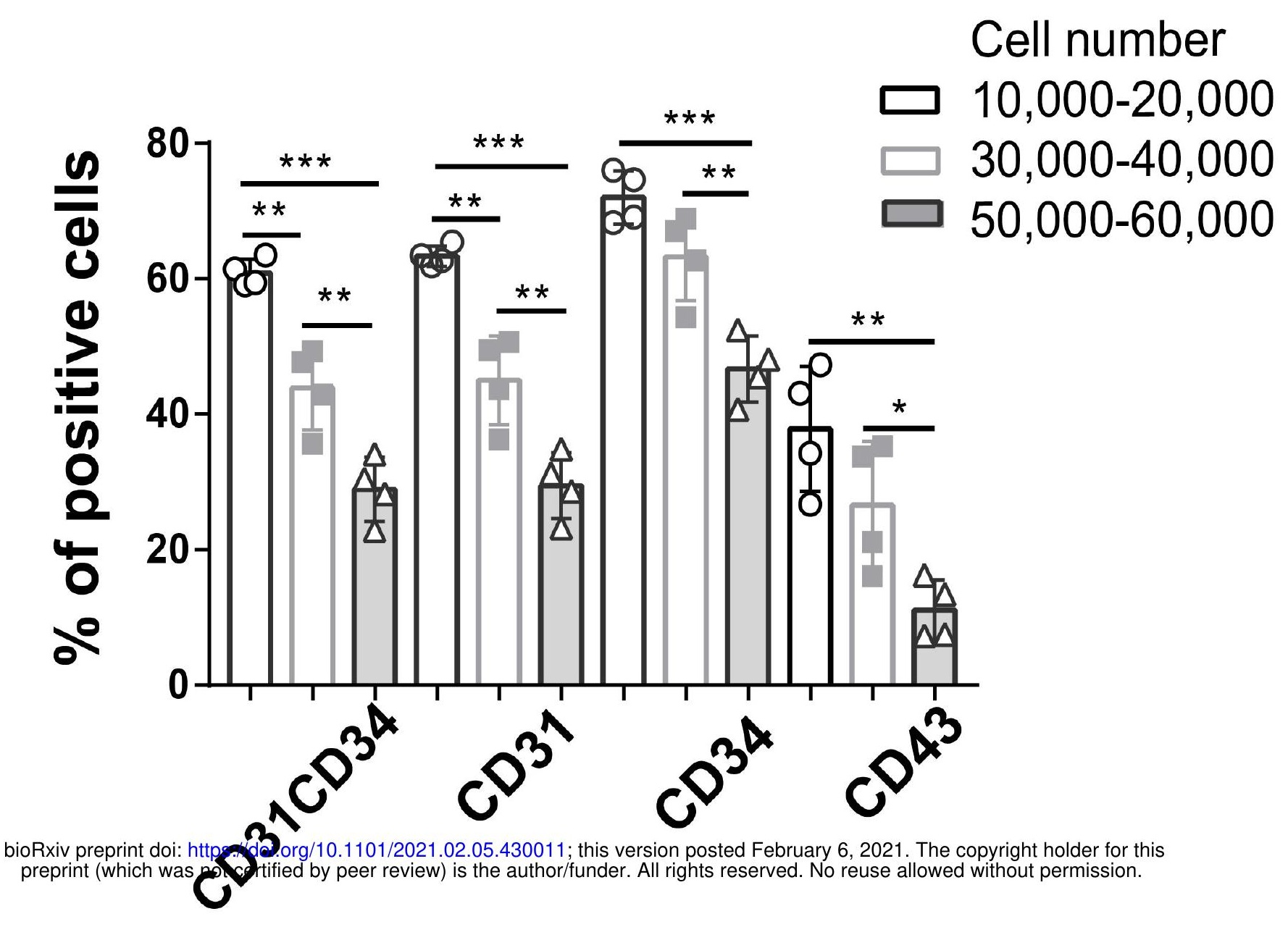

D
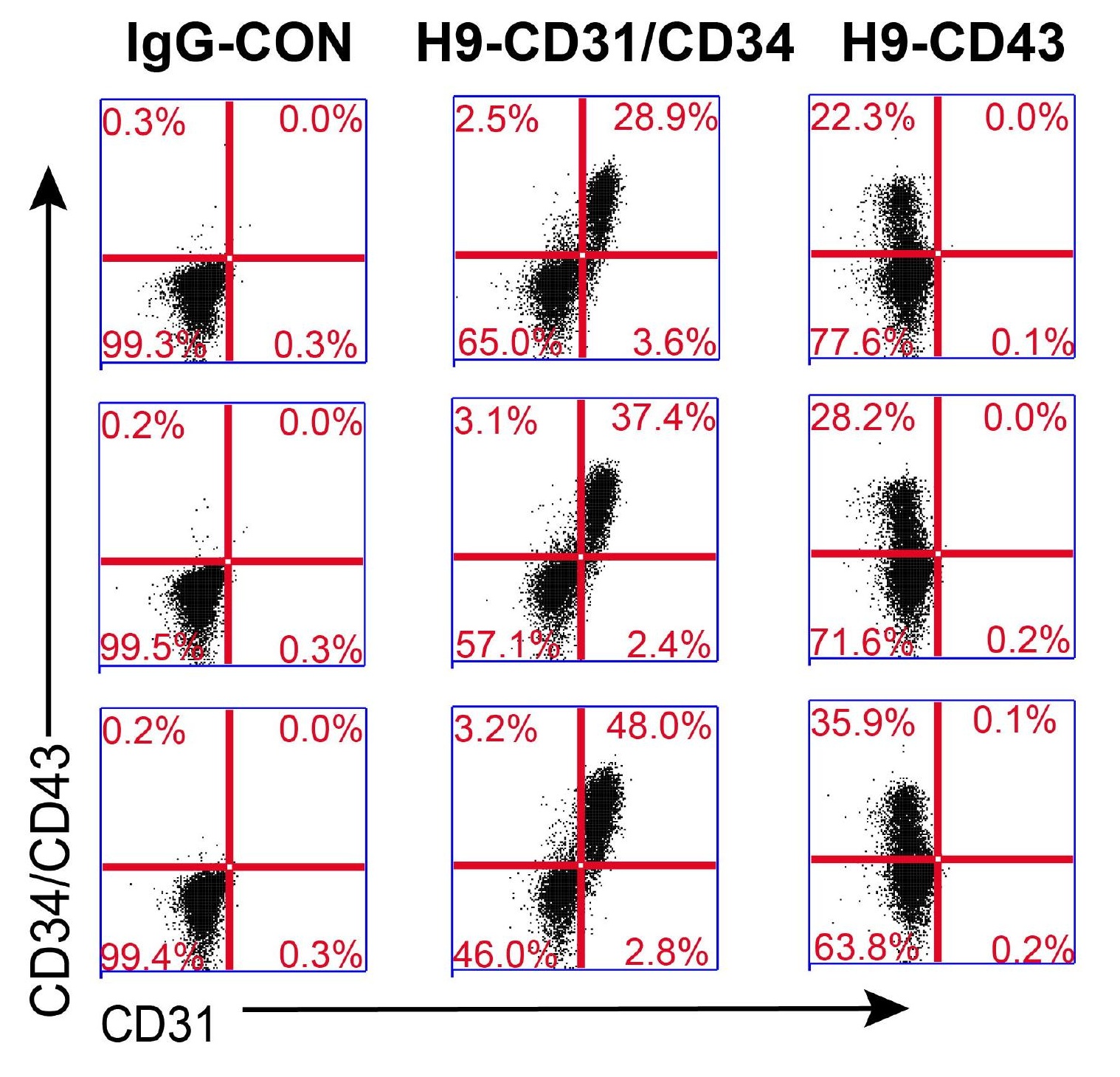

$\mathrm{SB} 431542$

$5 \mathrm{uM}$

10uM

20uM

E

C

FGF2

VEGF

BMP4 II

SB431542

G

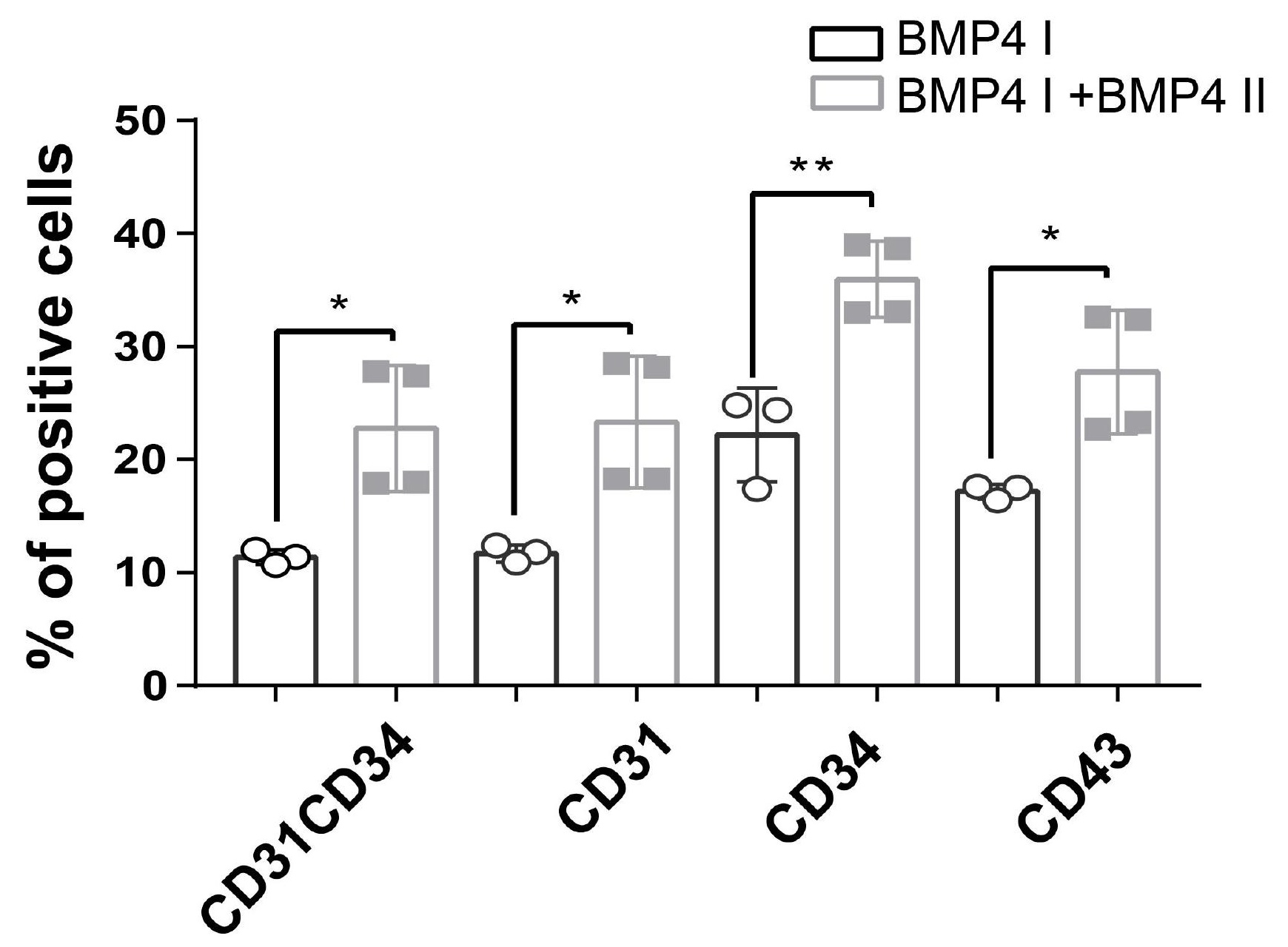

IgG-CON 202-CD31/CD34 202-CD43

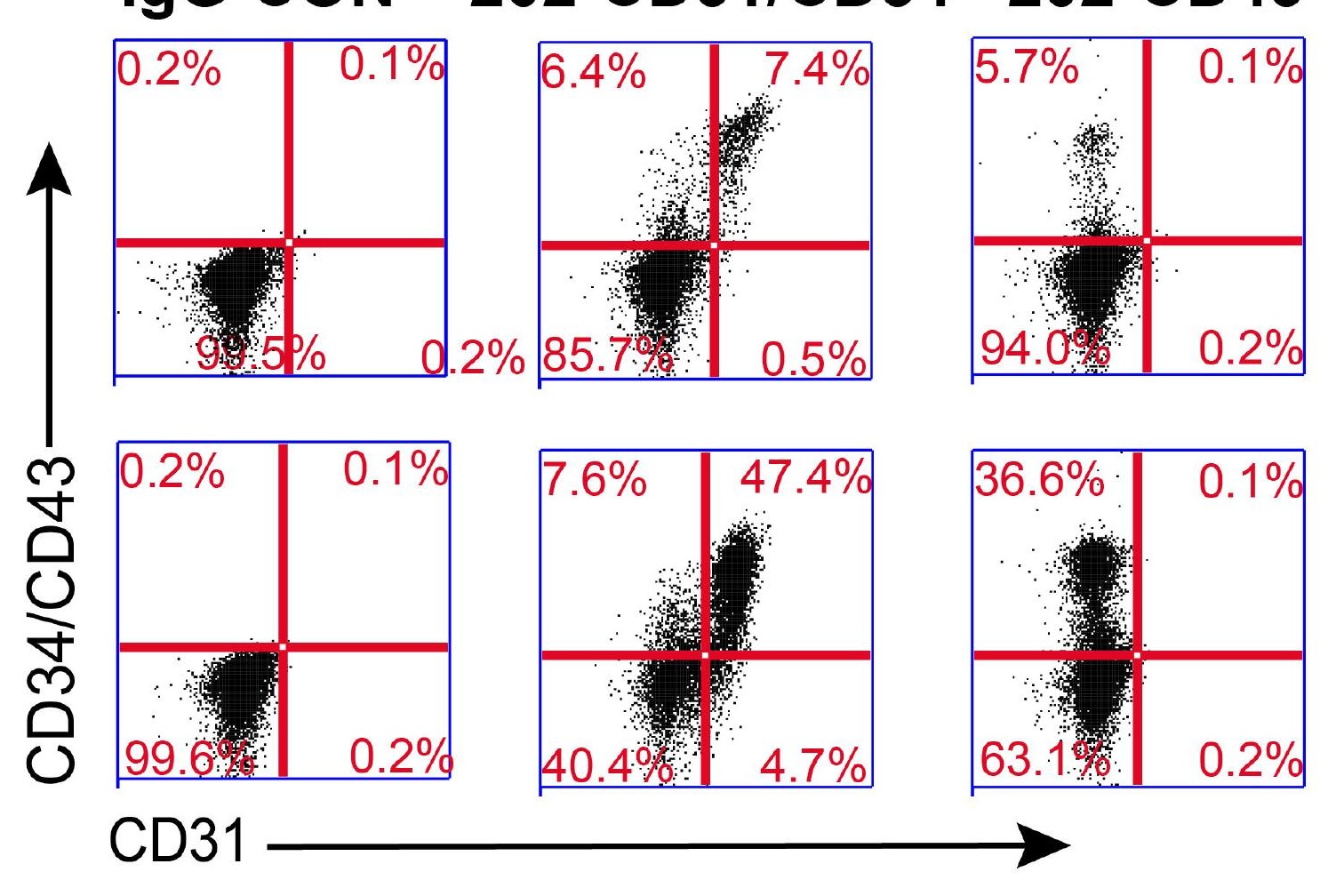

Y27632

1 day

3 days
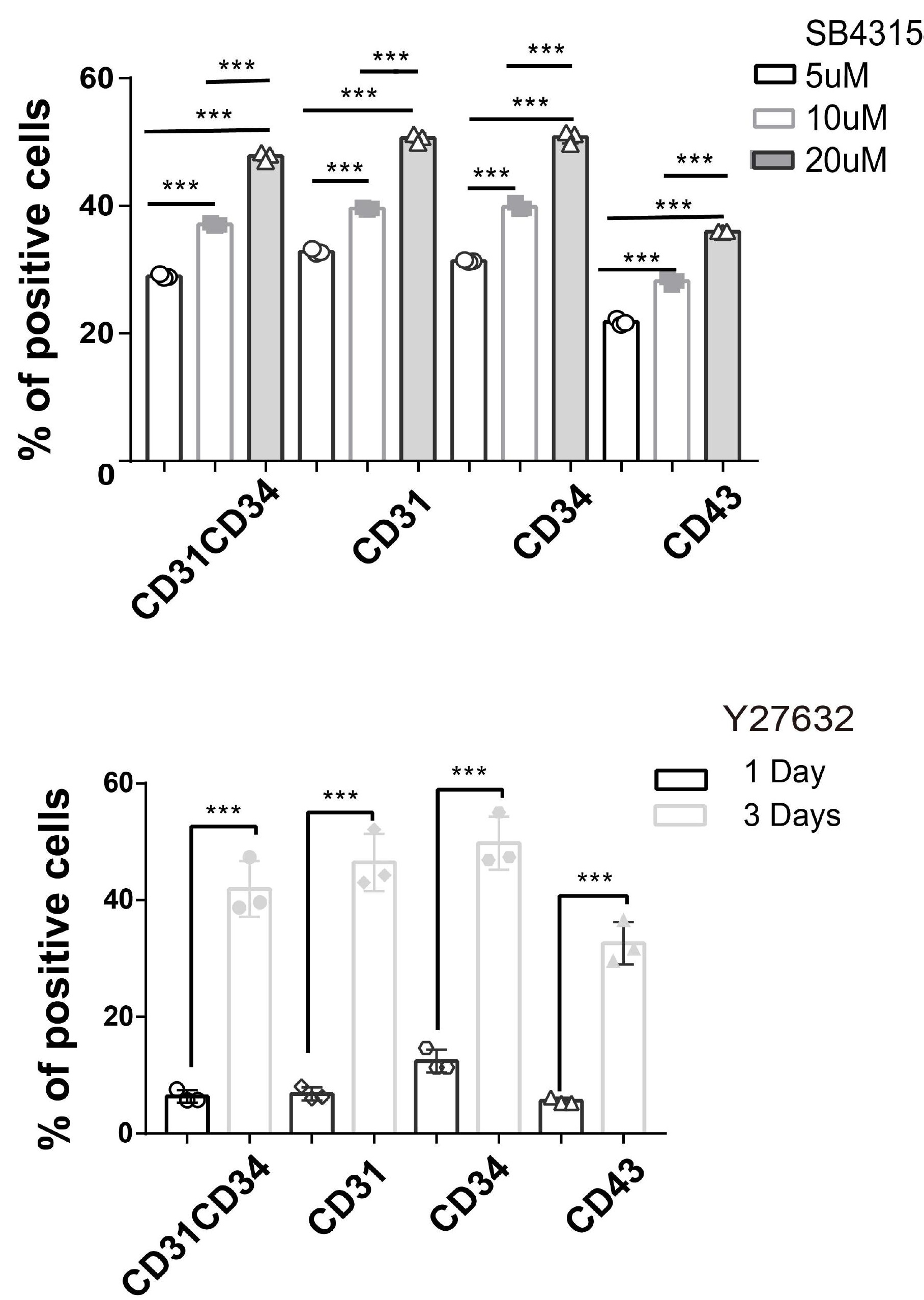

1 Day 3 Days 
Y27632

IgG-CON H1-CD31/CD34

H1-CD43

DMSO
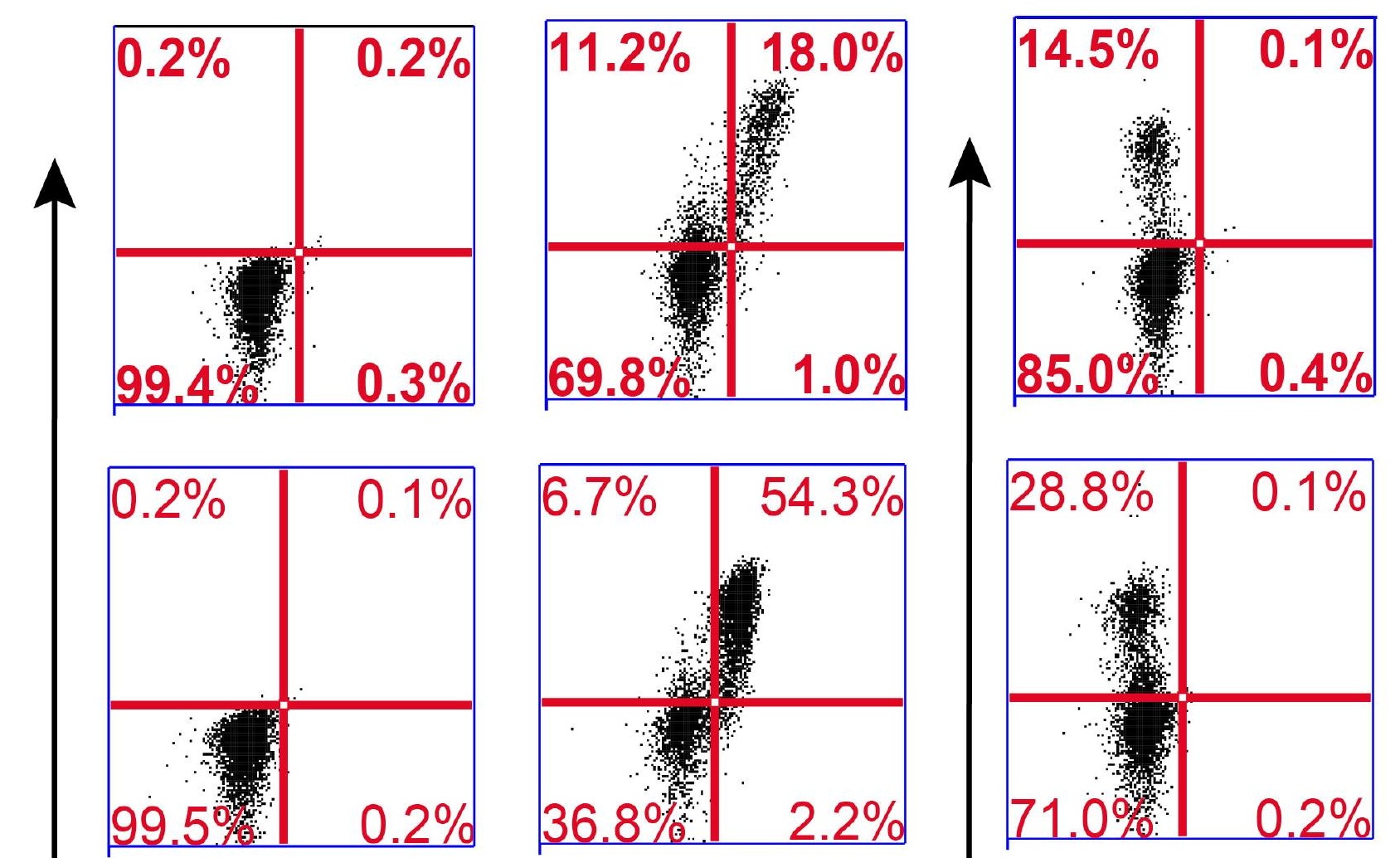

1 day

+DMSO
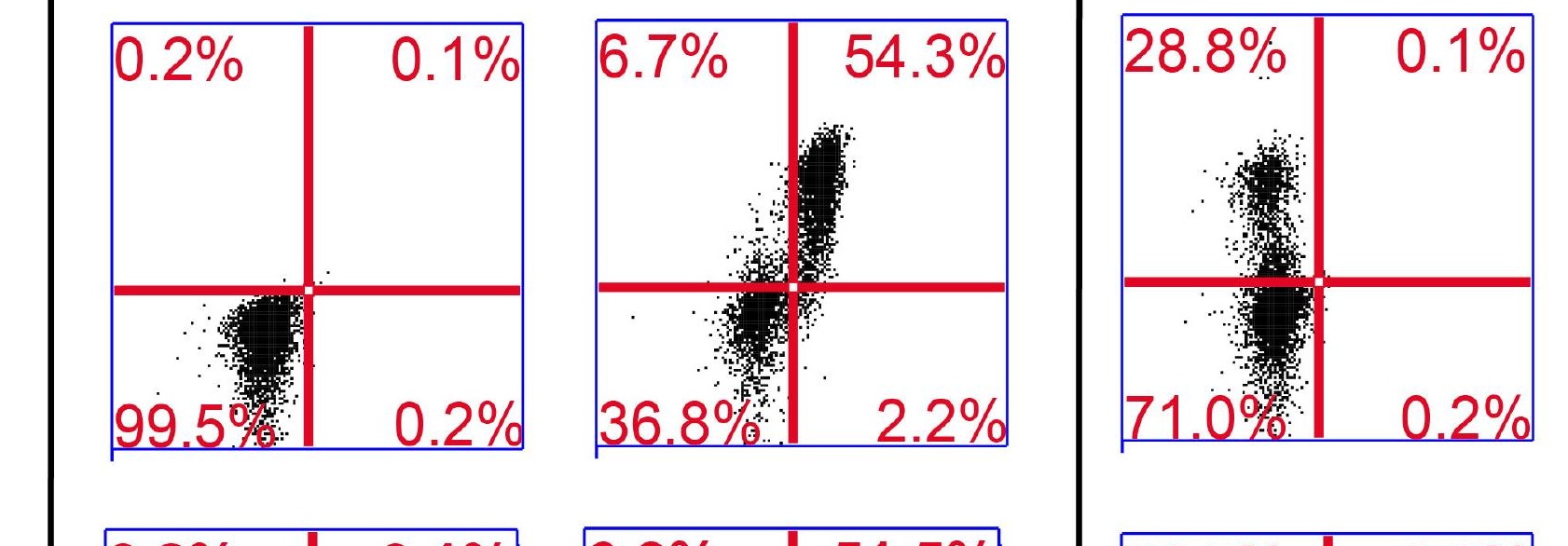

3 days

-DMSO
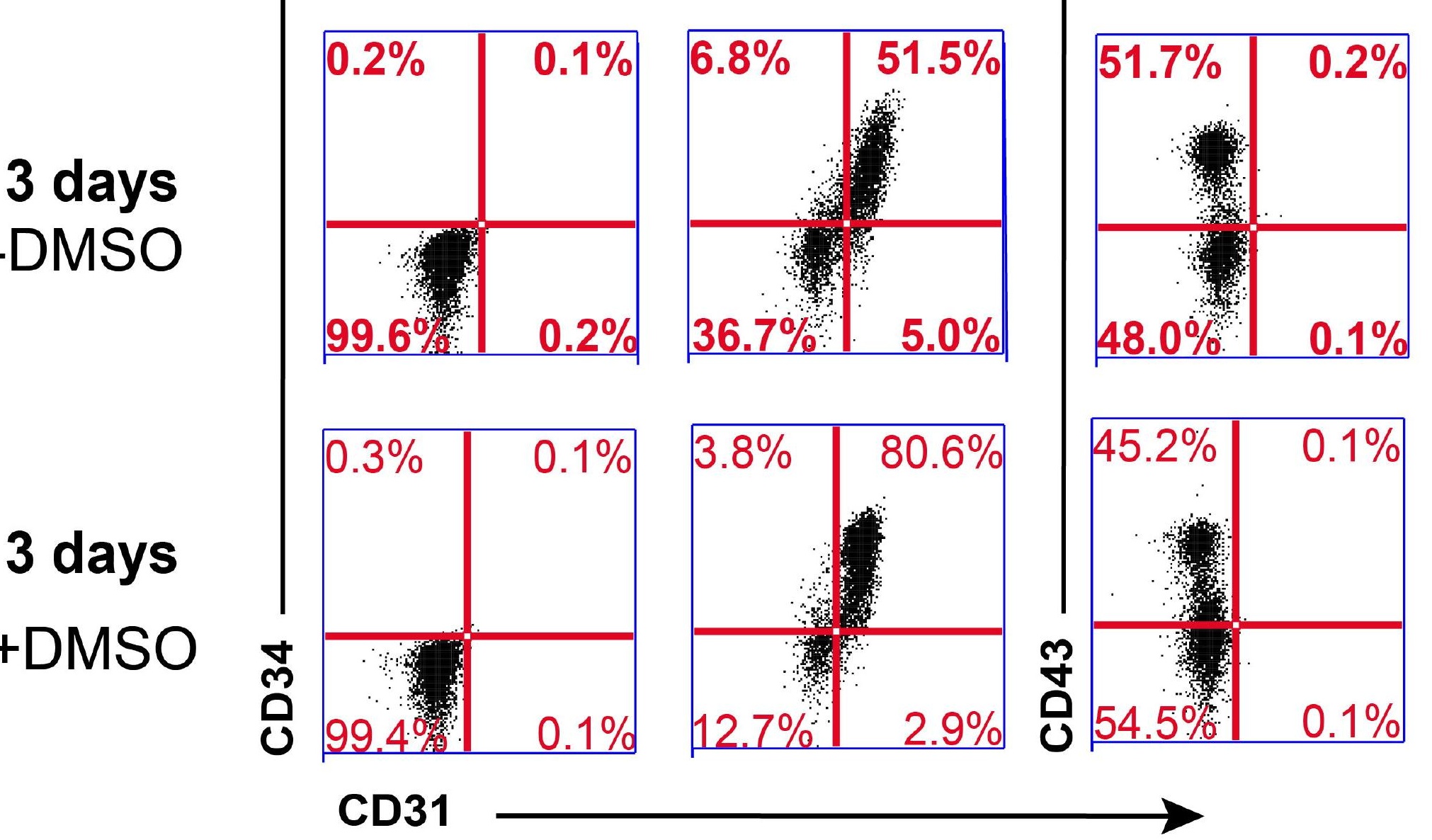

C

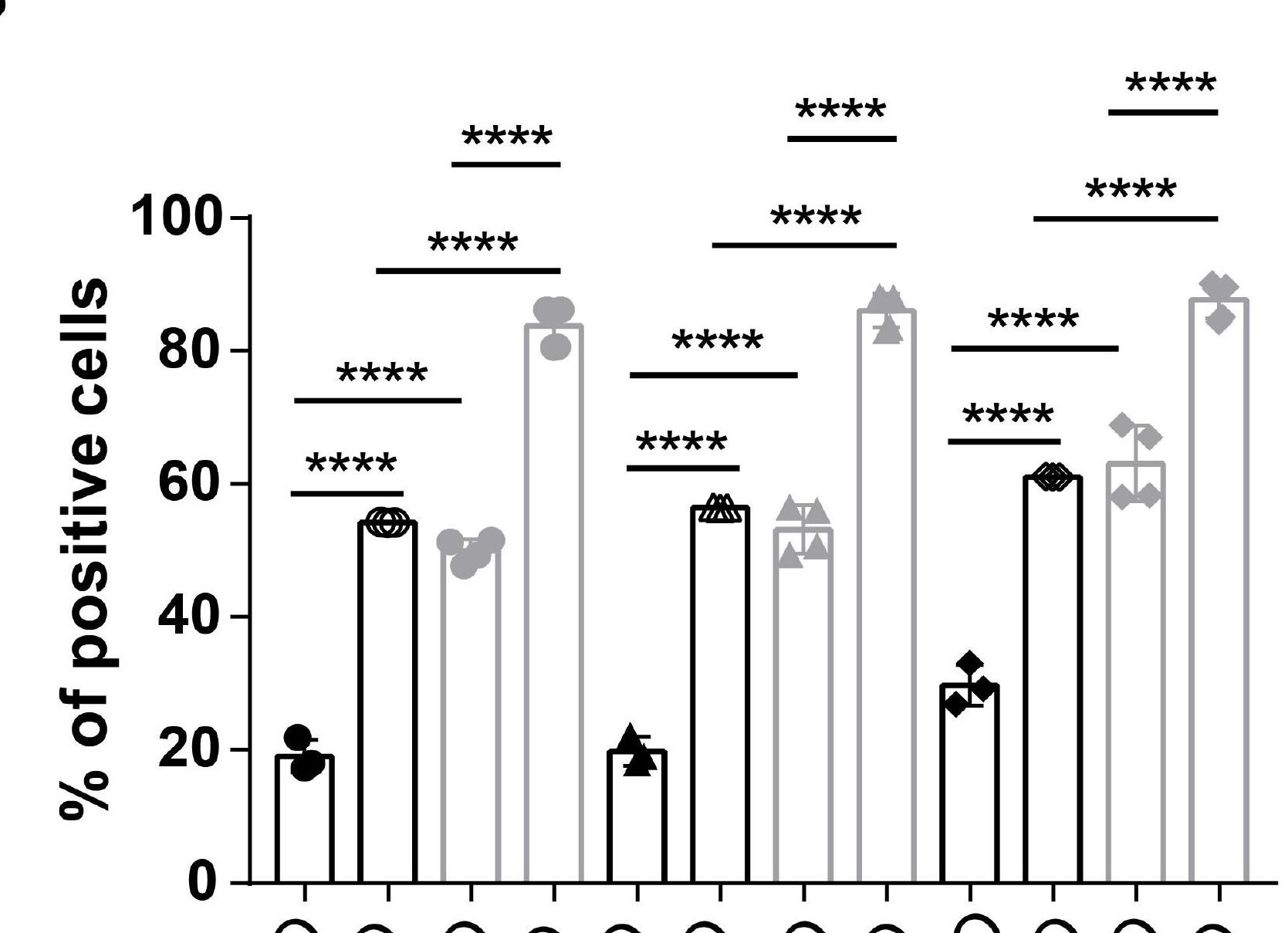

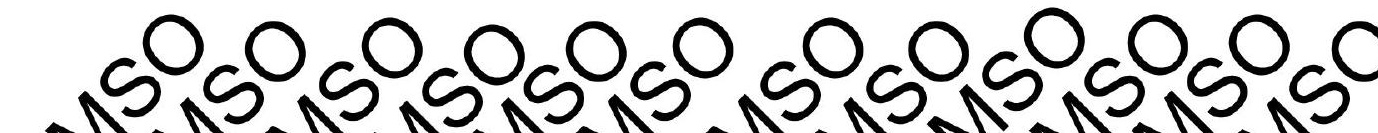

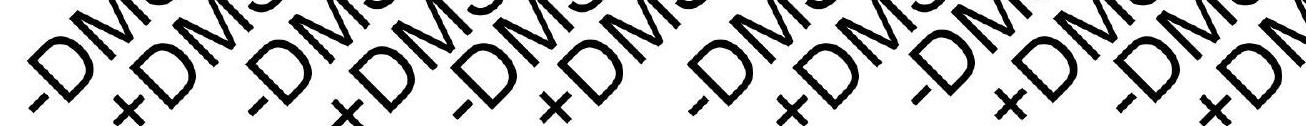

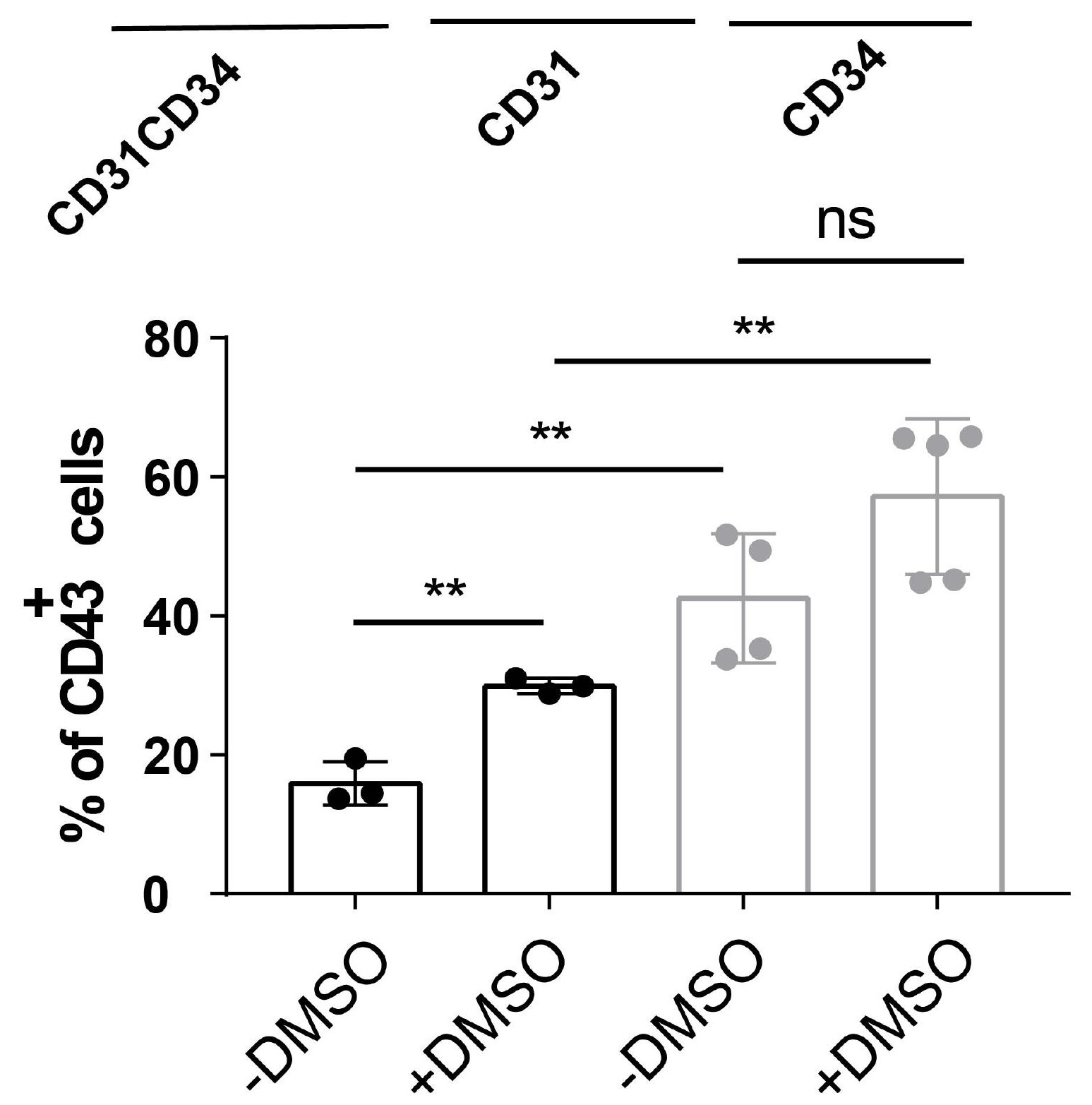

$\begin{array}{rlll}\text { hESC } & \text { APLNR+ } & \text { CD31+CD34+ } & \text { CD43+ }\end{array}$

\begin{tabular}{llll} 
D0 & \multicolumn{1}{c}{ D3 } & \multicolumn{1}{c}{ D5 } & FGF2 50ng \\
ActivinA 50ng & FGF2 50ng & VE \\
BMP4 40ng & VEGF 40ng & VEGF 40ng \\
& & &
\end{tabular}
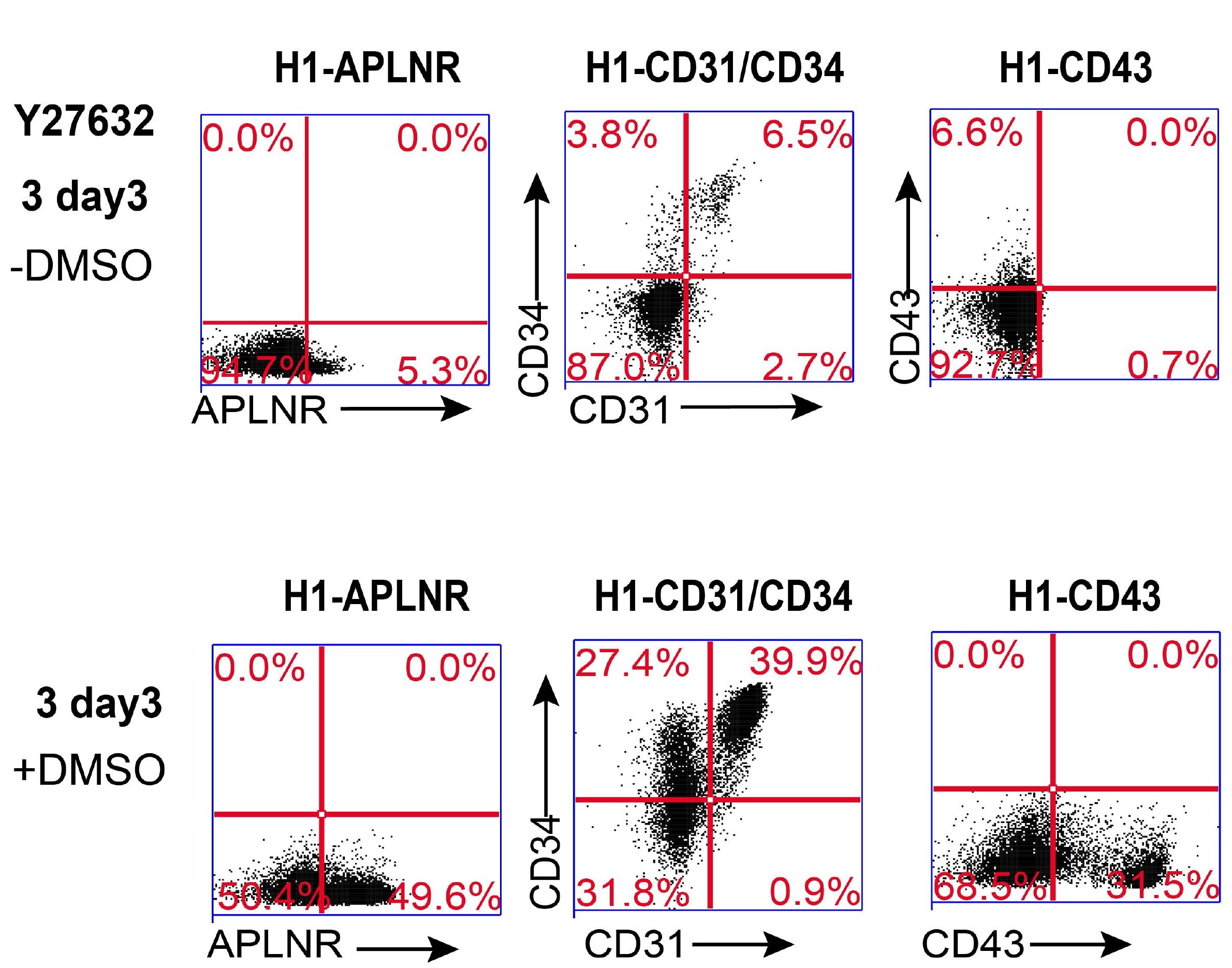
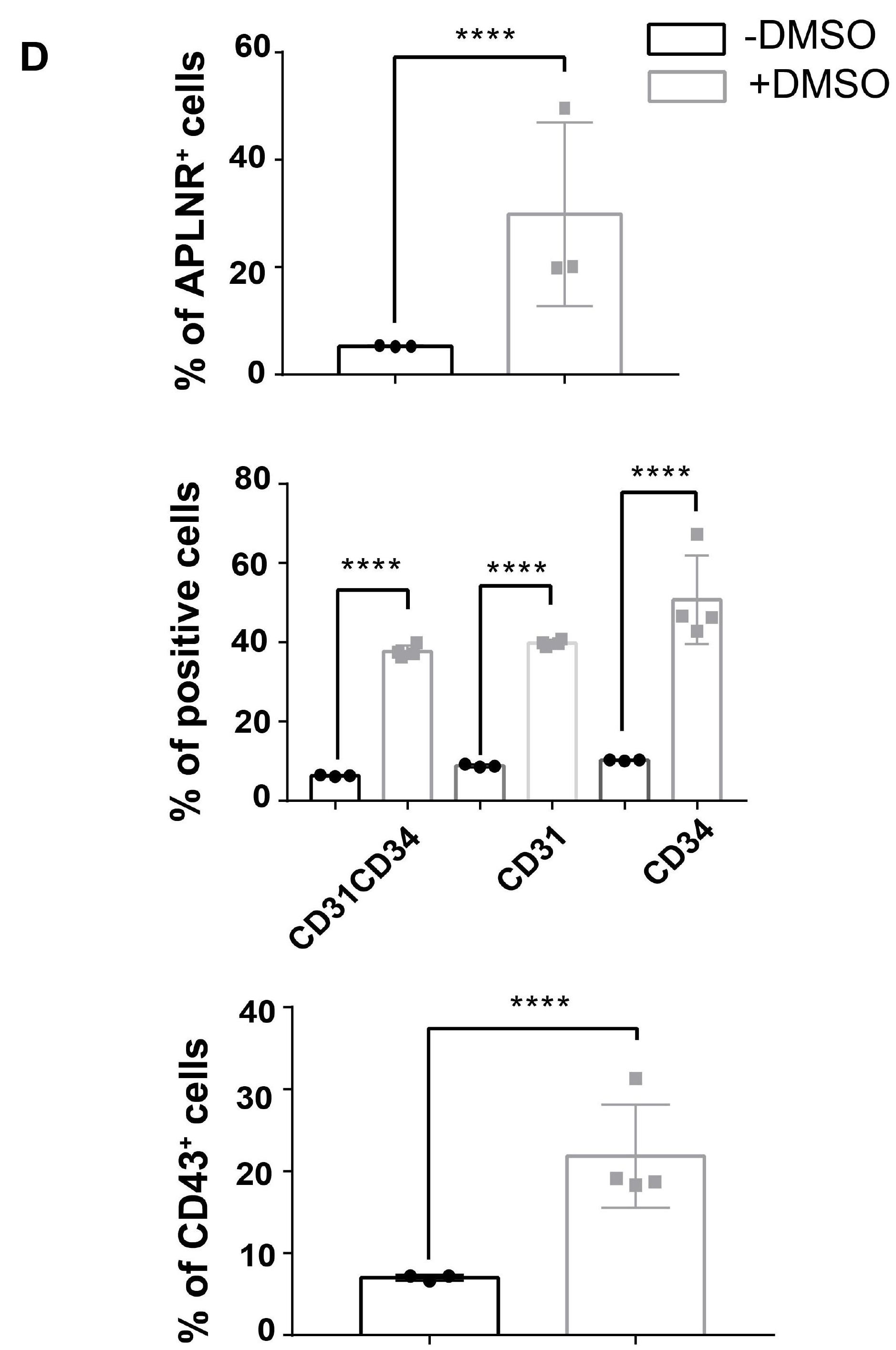
hESC

APLNR $^{+}$cell

D0

\section{ActinA} BMP4

Y27632

DMSO
CD31 ${ }^{+} / \mathrm{CD}^{3} 4^{+}$cell and $\mathrm{CD}^{+} 3^{+}$cell

-8.

D7
FGF2

VEGF

BMP4

SB431542
IgG-CON

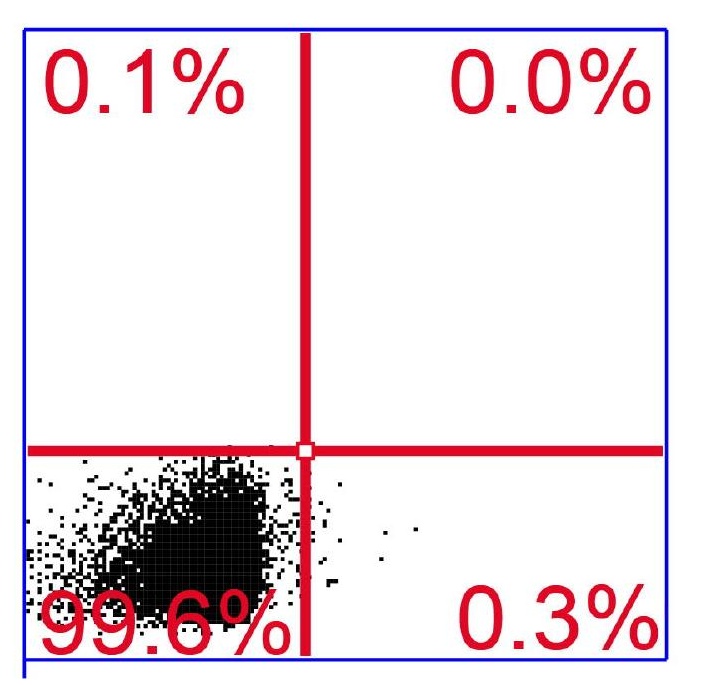

APLNR
H1-APLNR

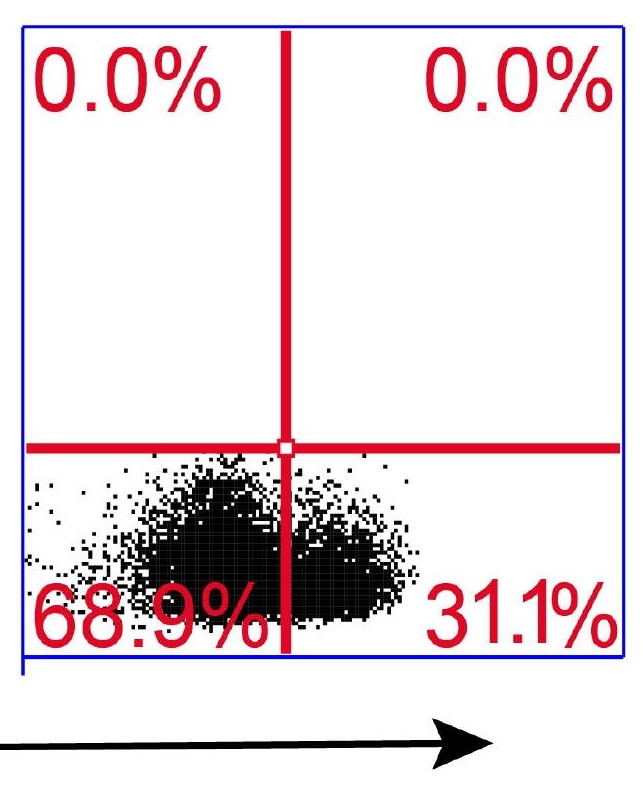

D

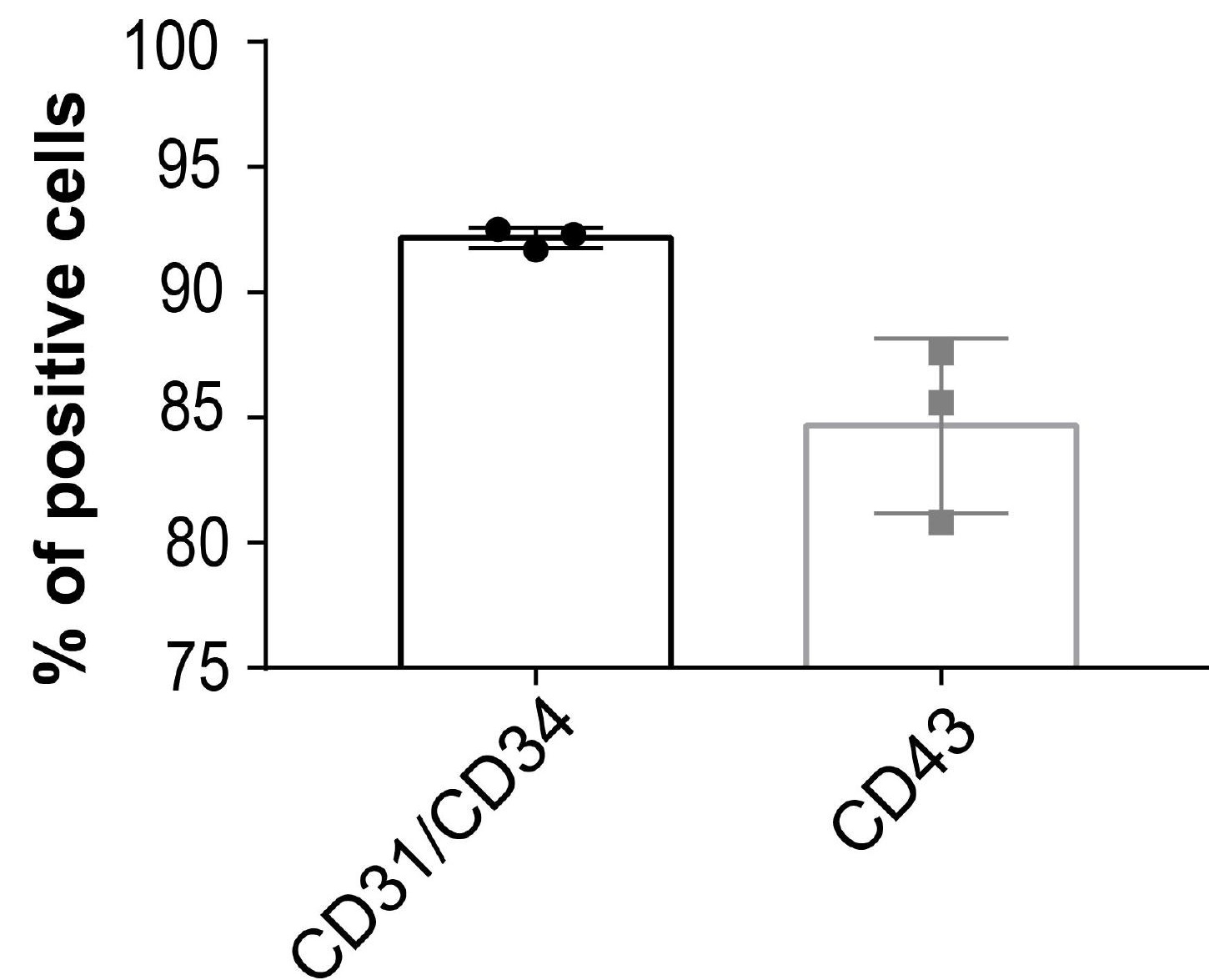


$\mathbf{A}$

Brightfield

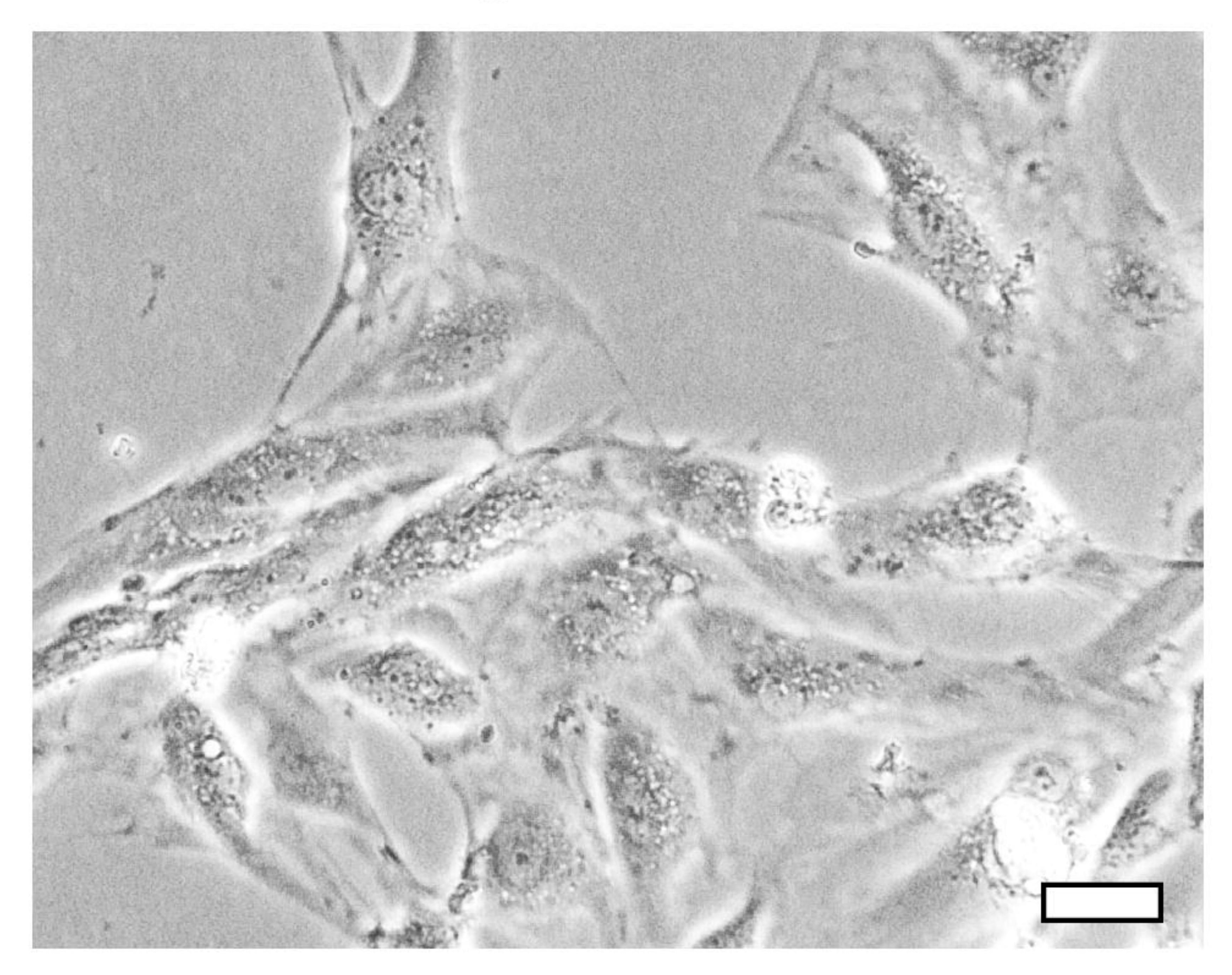

Dil-LDL

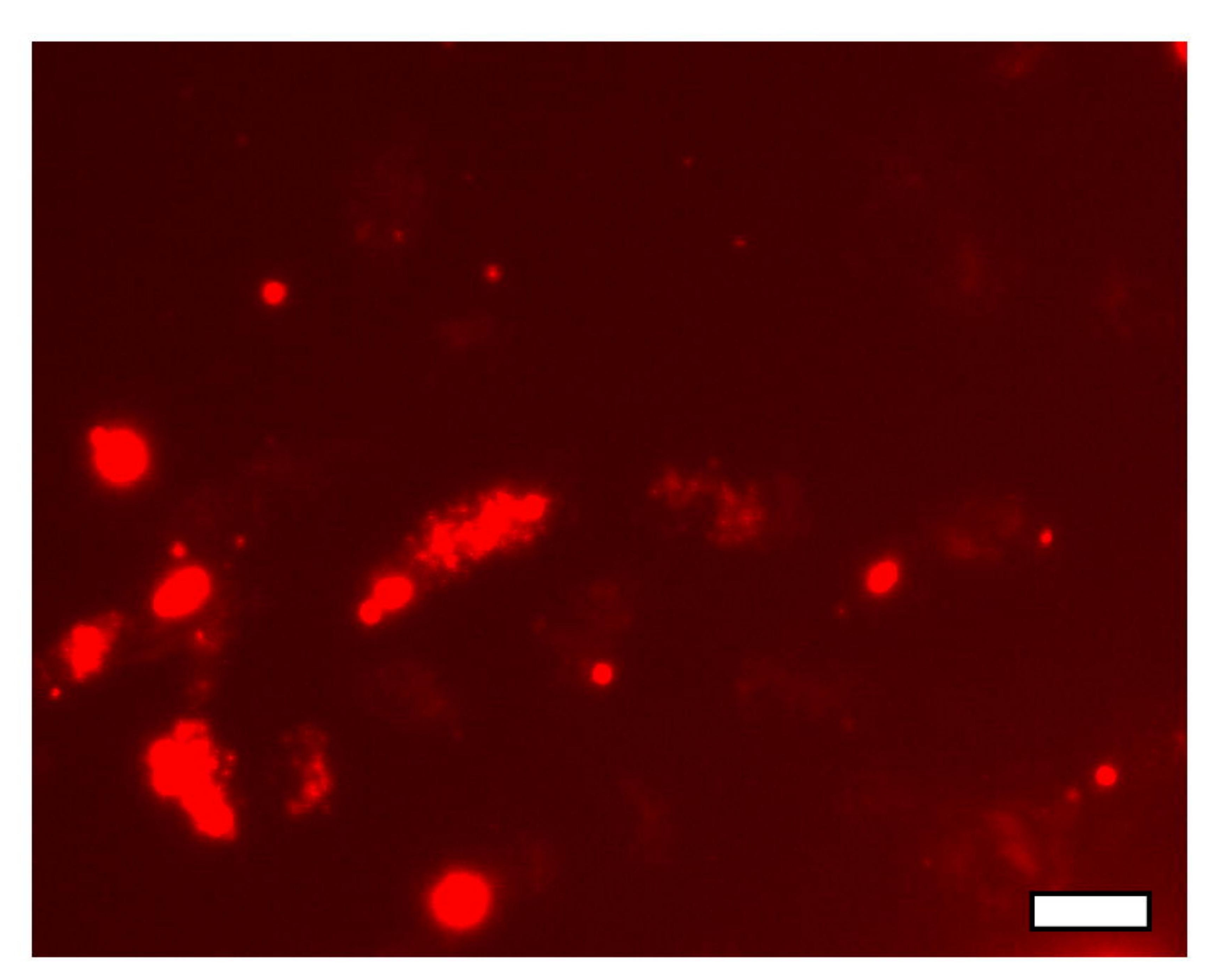

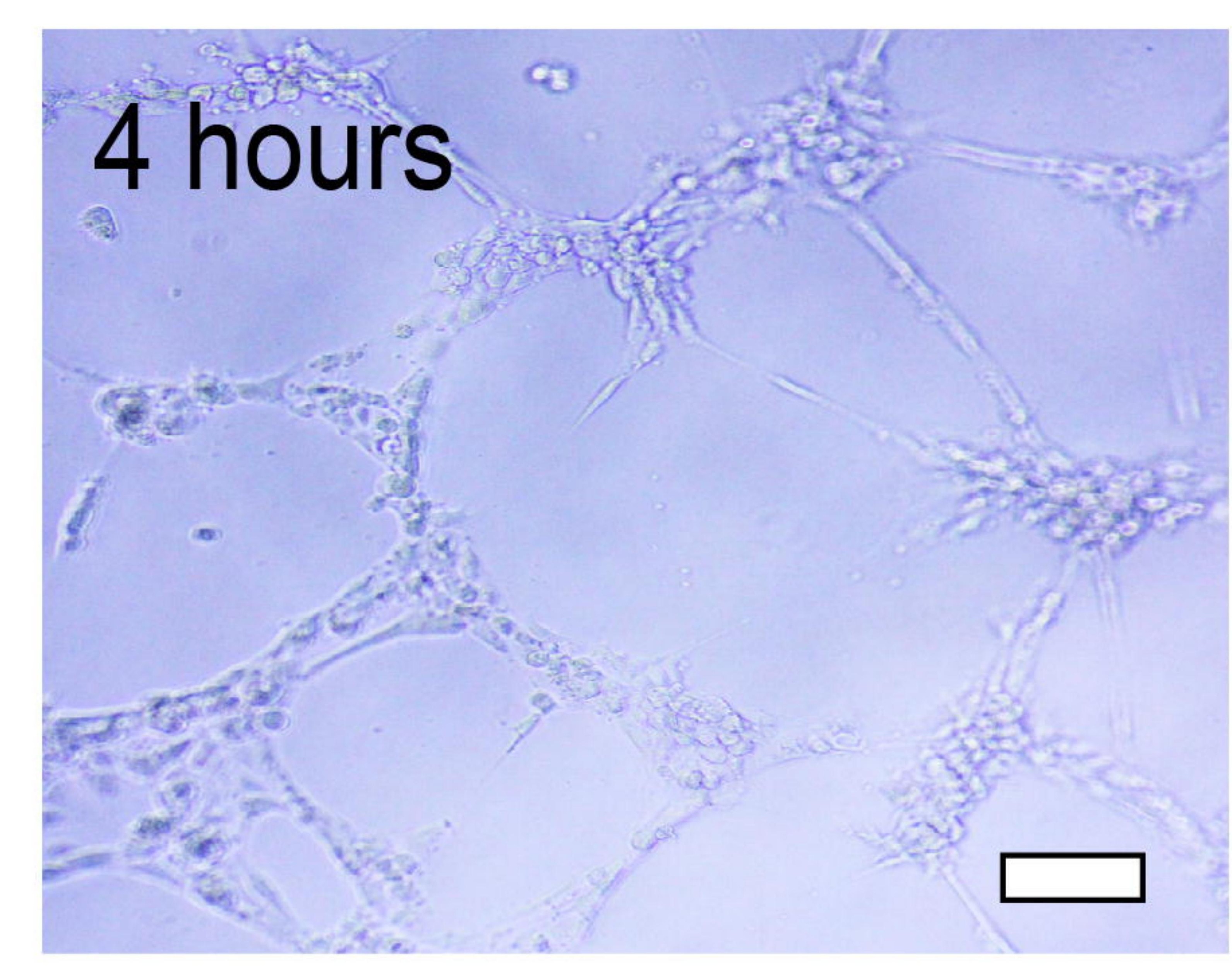

12 hours

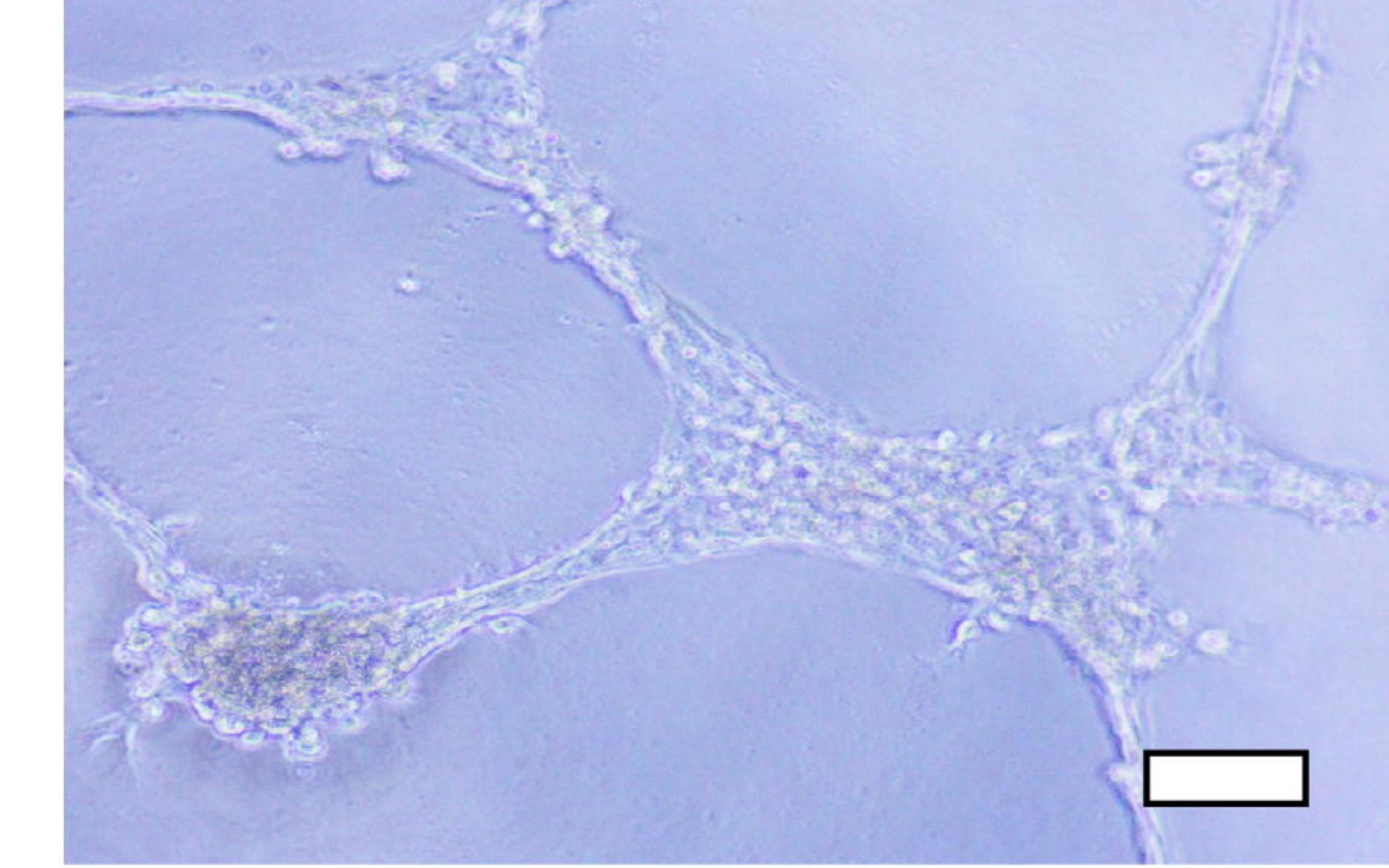

Zebrafish embryos
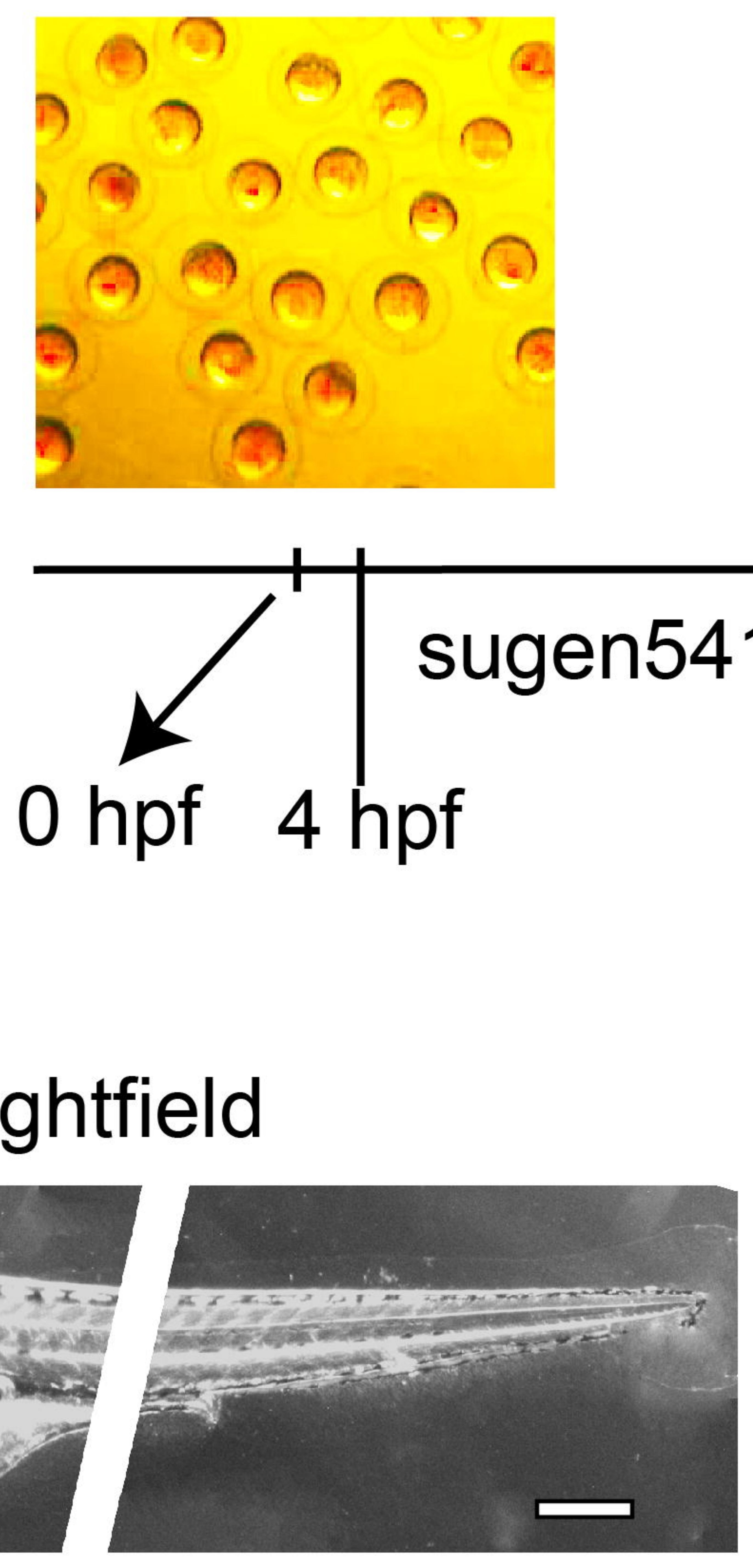

Dil-RED
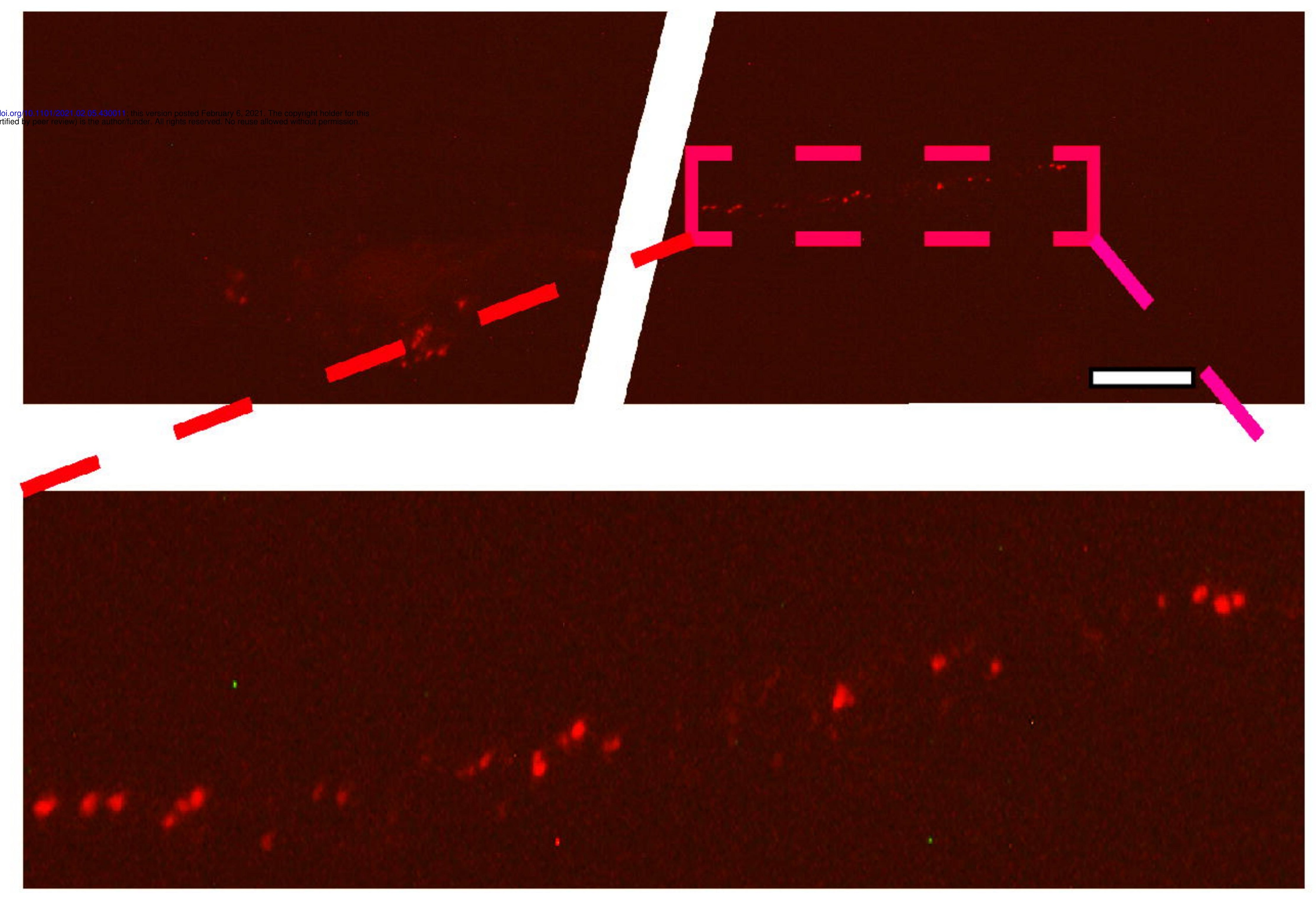

$\therefore$ PSC-derived EPCs
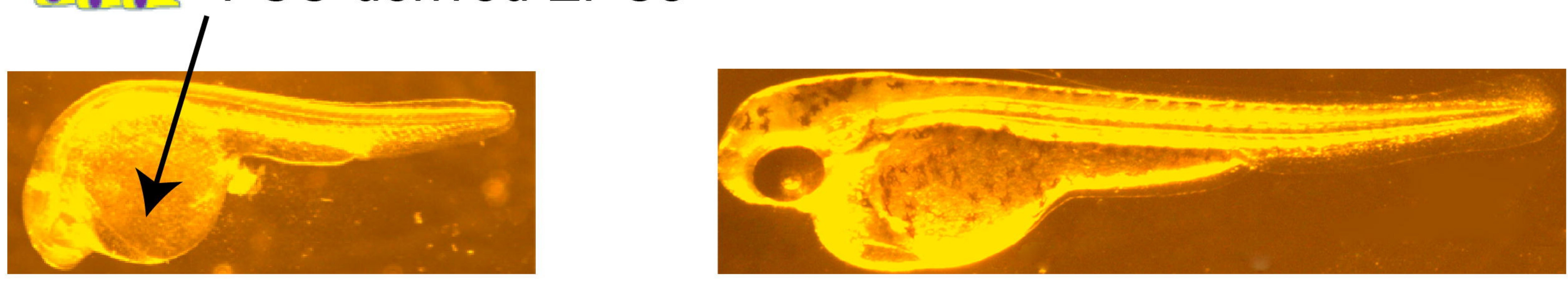

$52 \mathrm{hpf}$

100 hpf -124hpf
D

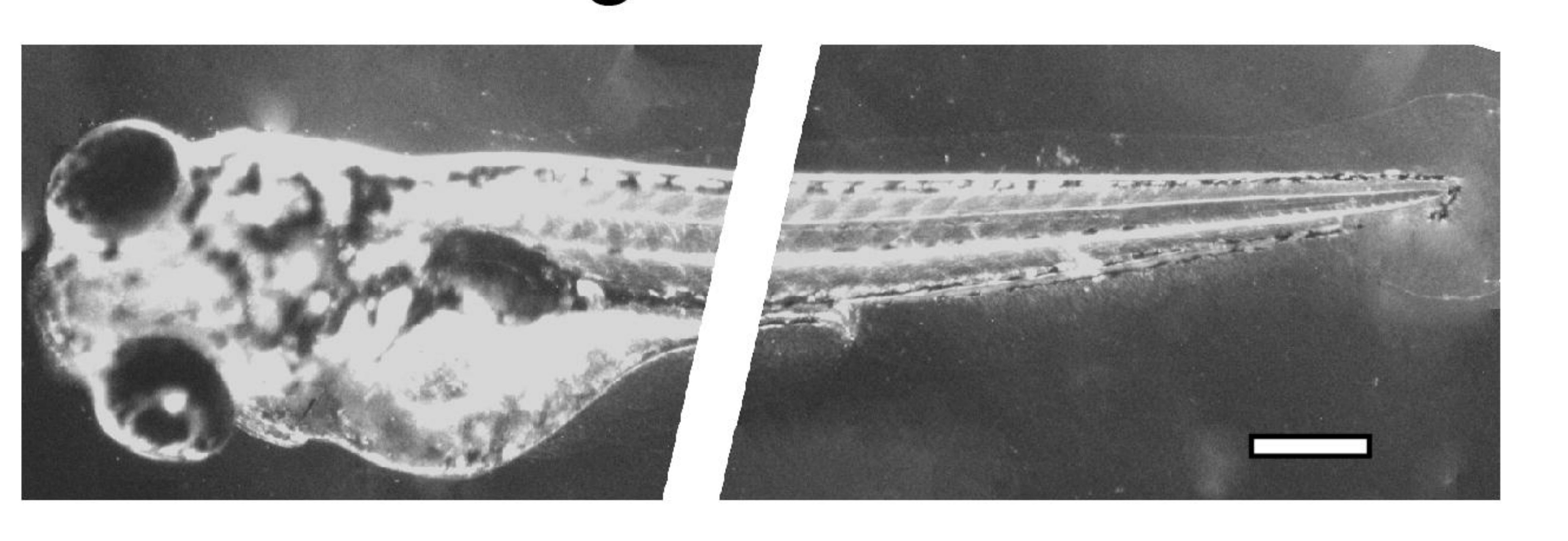

$28 \mathrm{hpf}$

Flk+:GFP

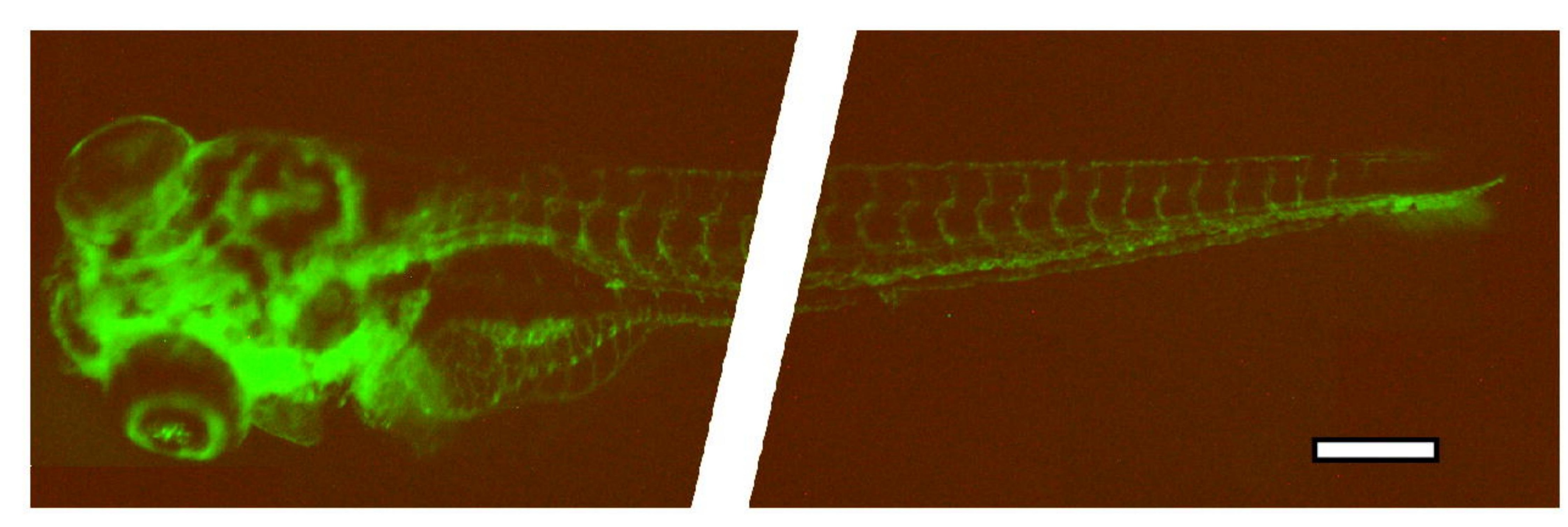

Merge

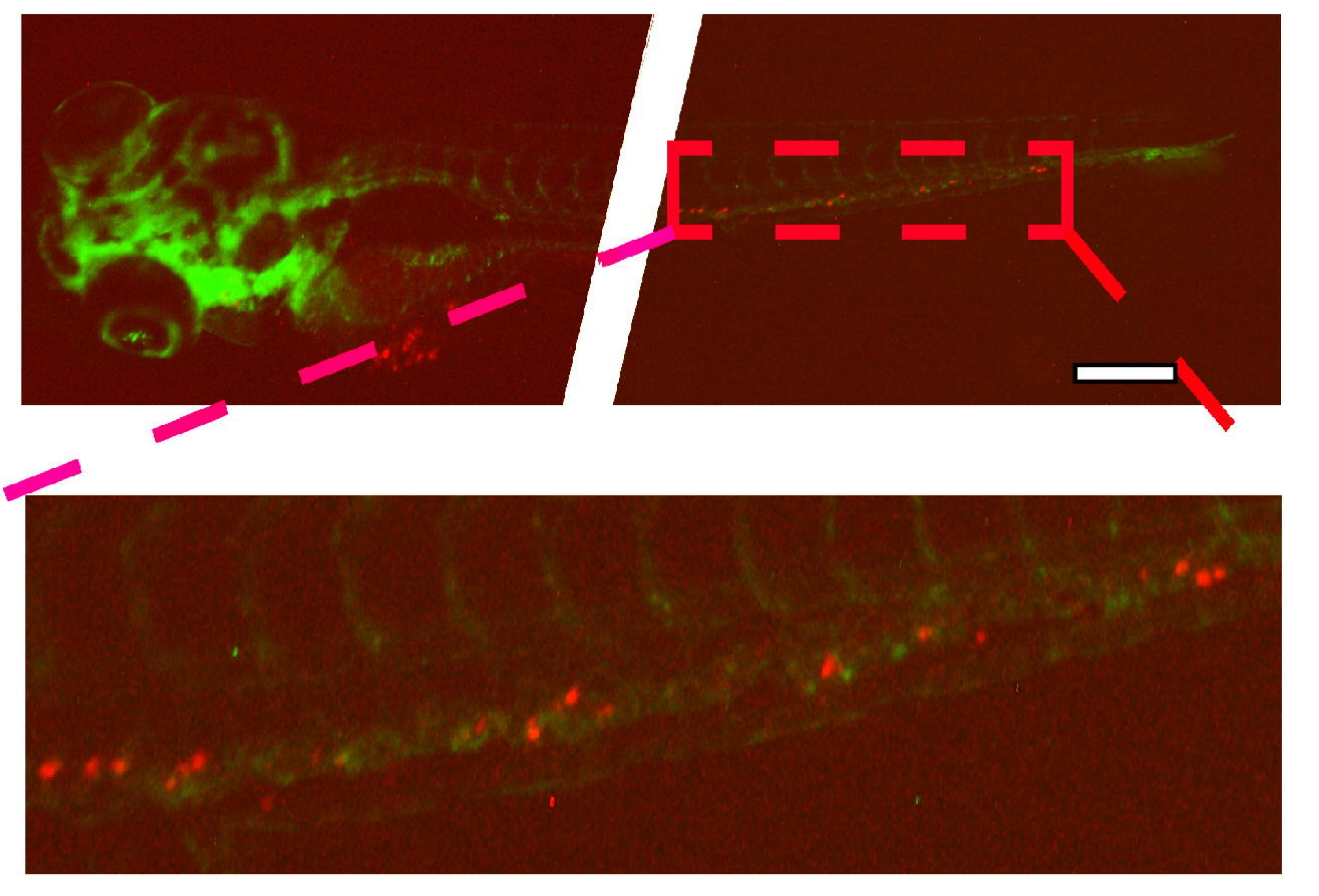

E

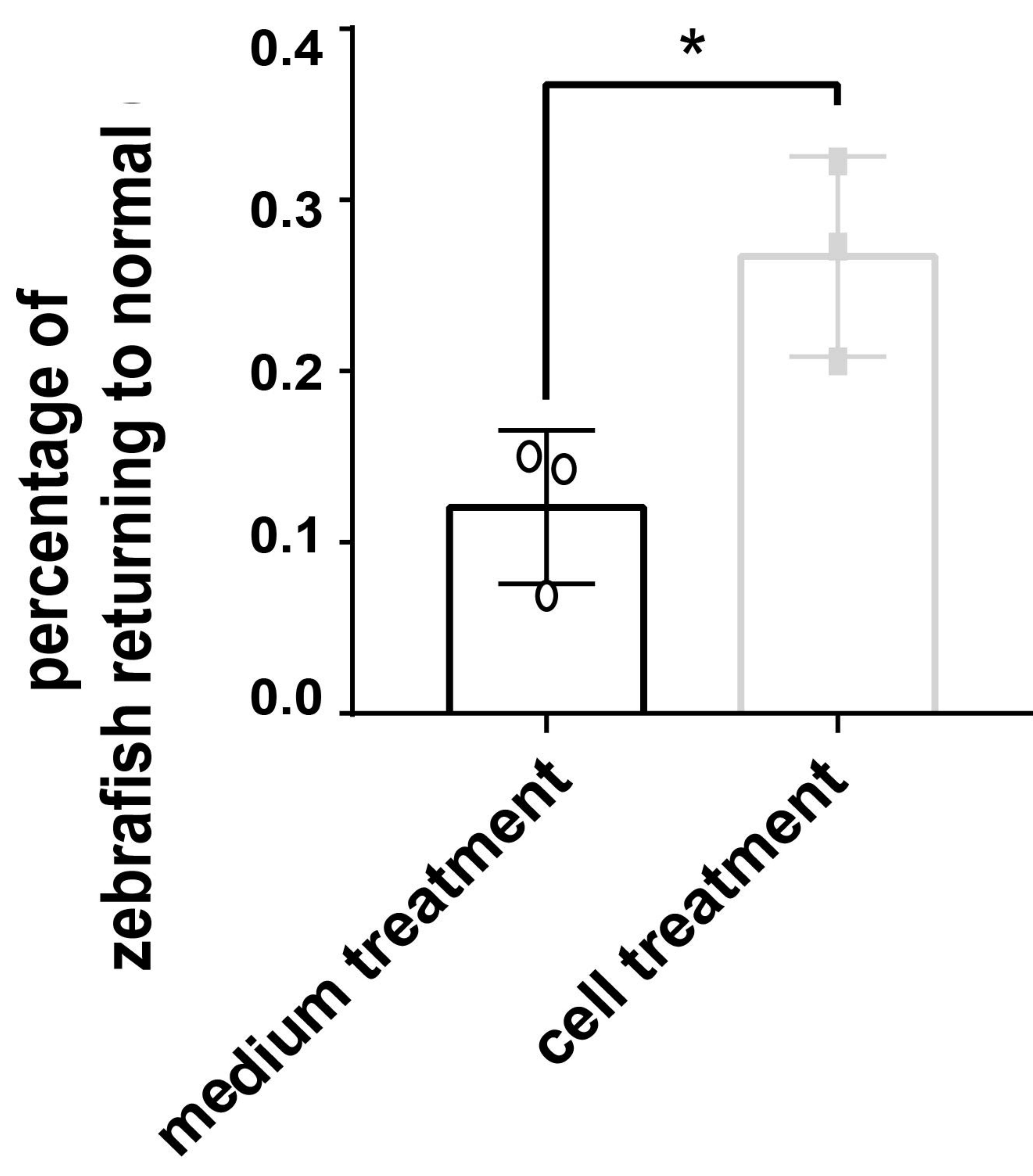


$\mathbf{A}$

\section{Normal EPC1}

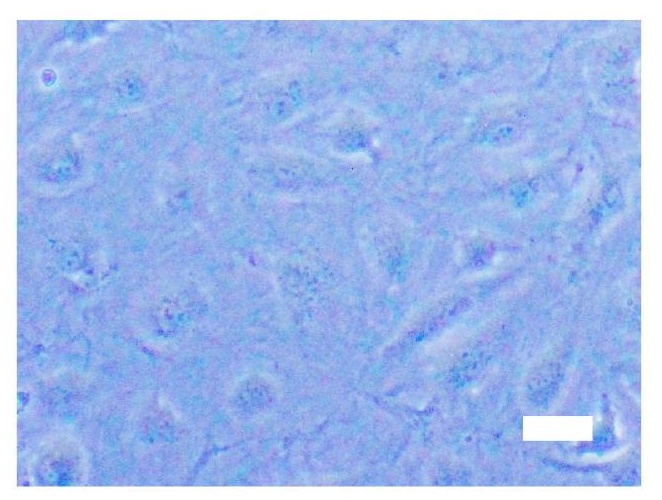

H7EC

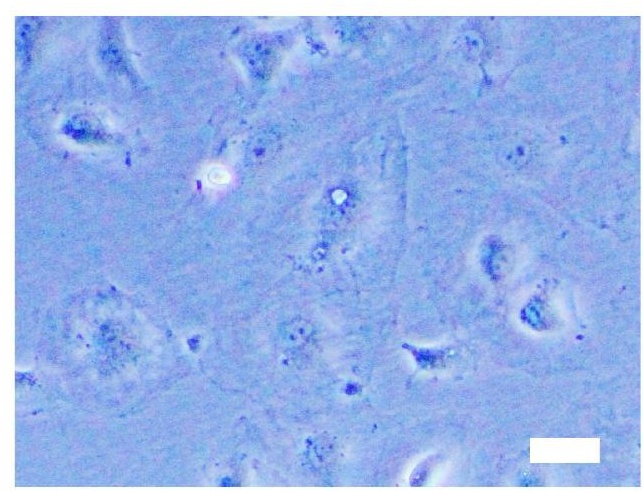

IPAH EPC1

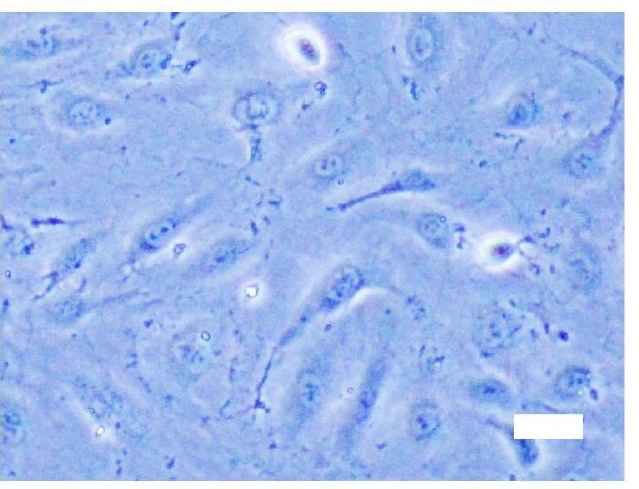

Normal EPC2

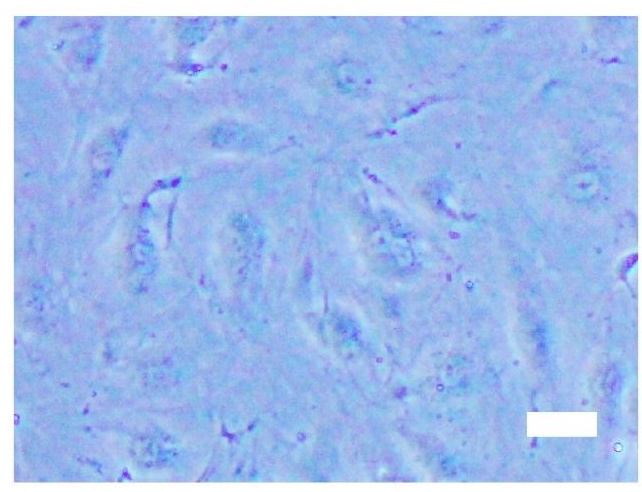

\section{EC}

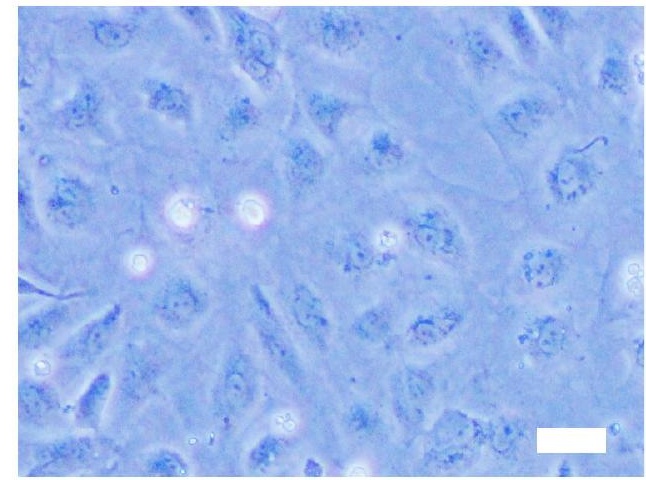

IPAH EPC2

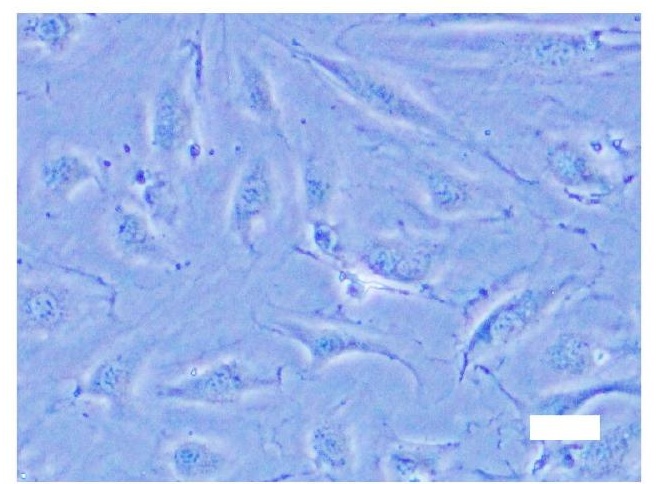

B $\quad$ $25 \quad$ NRP1

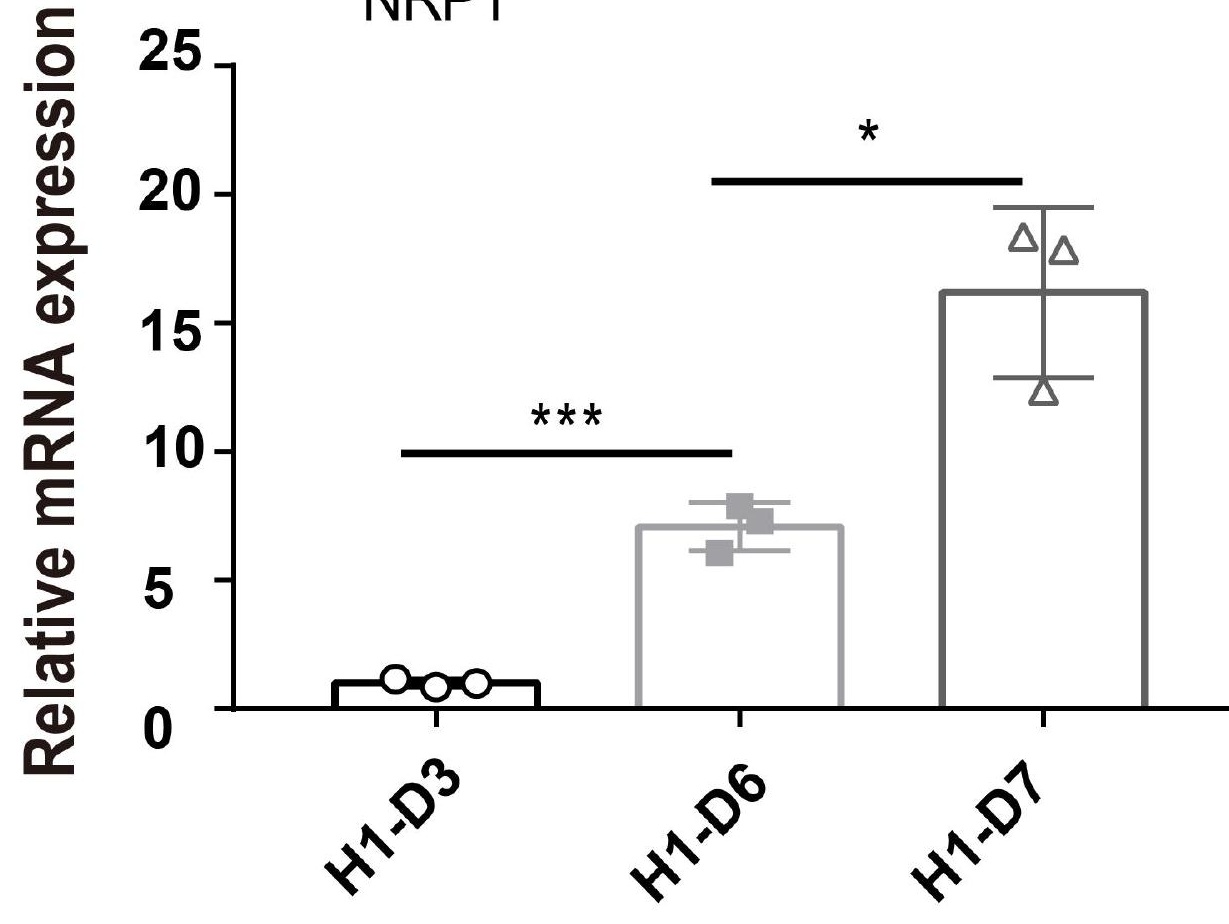

C

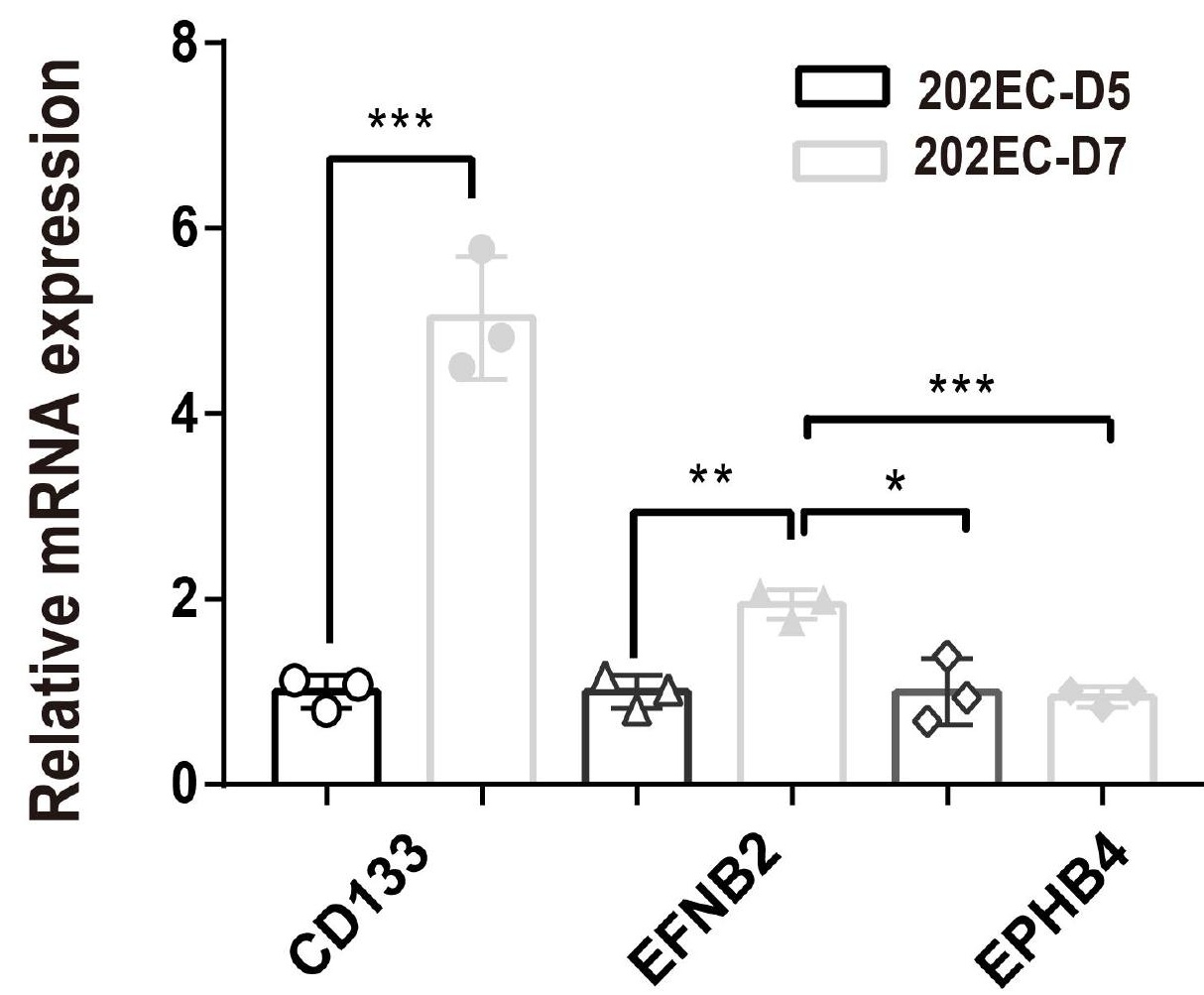


A

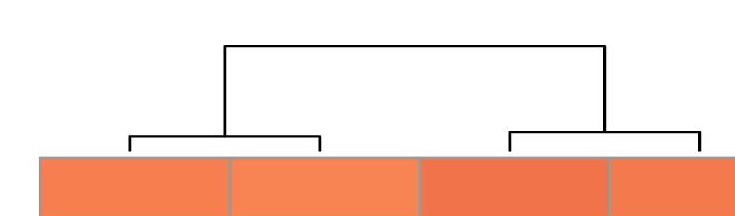

SPN

PTPRC

VWF

NRP1

KDR

EFNB2

EPHB4

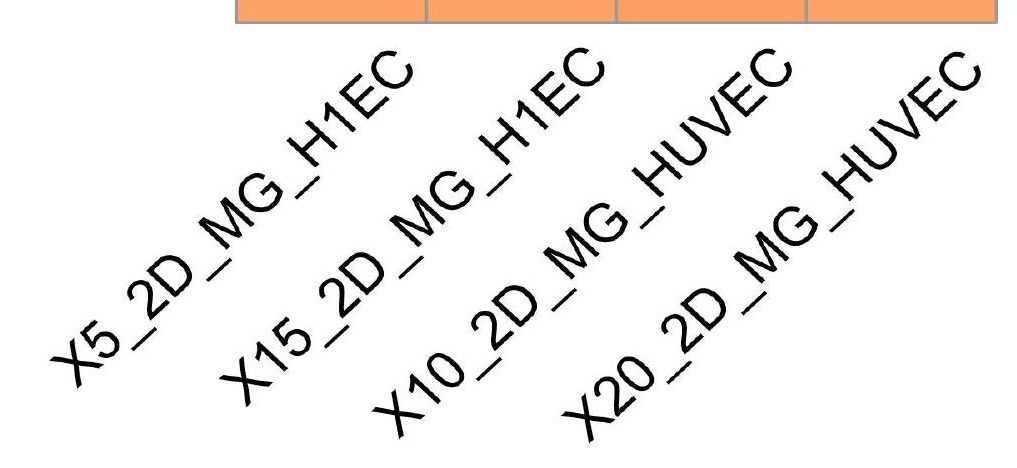

C

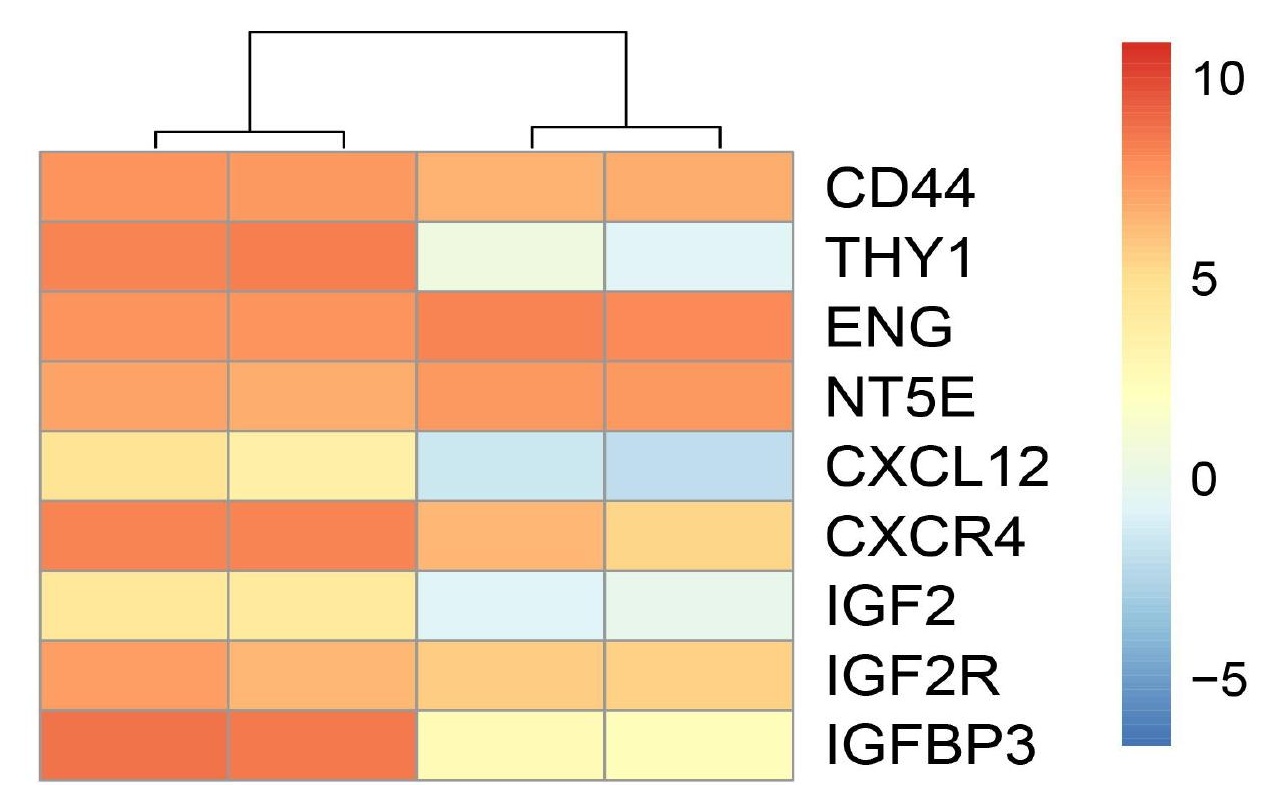

B

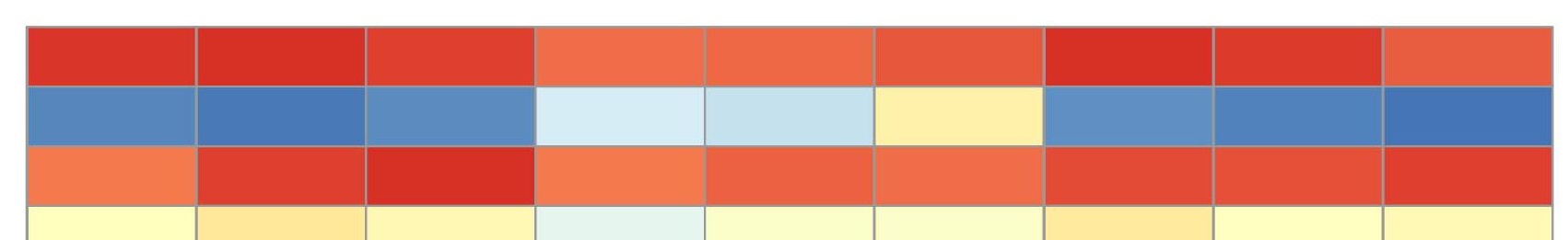

PECAM1

PROM1

MCAM

CD34

SPN

PTPRC

VWF

NRP1

KDR

EFNB2

EPHB4

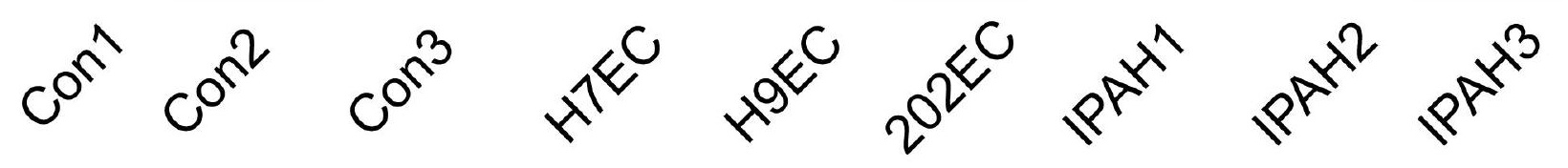

D

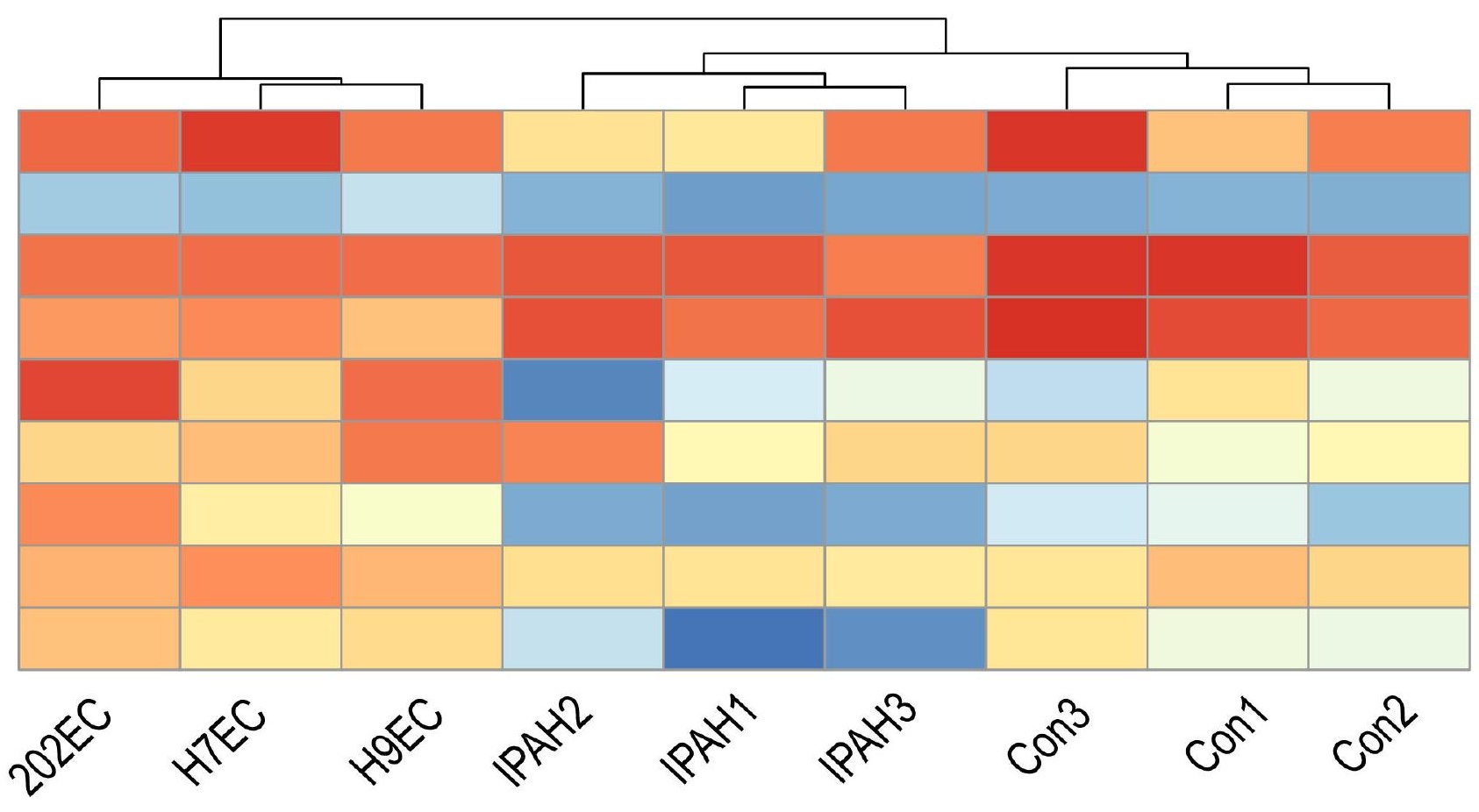

CD44

THY1

ENG

NT5E

CXCL12

CXCR4

IGF2

IGF2R

IGFBP3

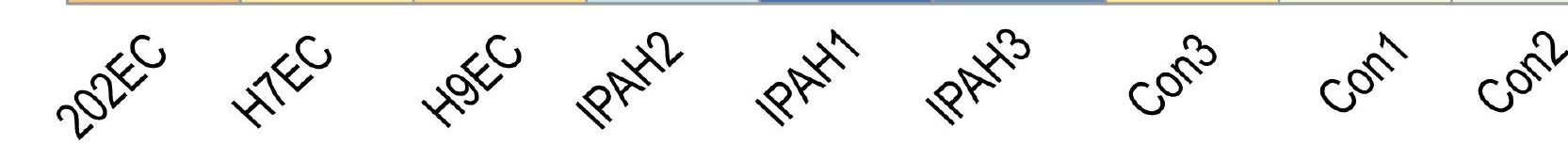

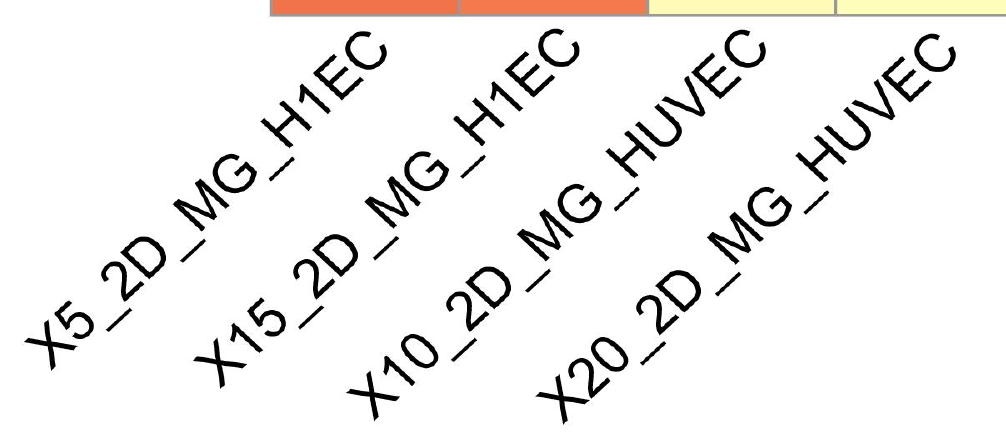

12

10

8

6

4

11
10
9
8
7
6
5




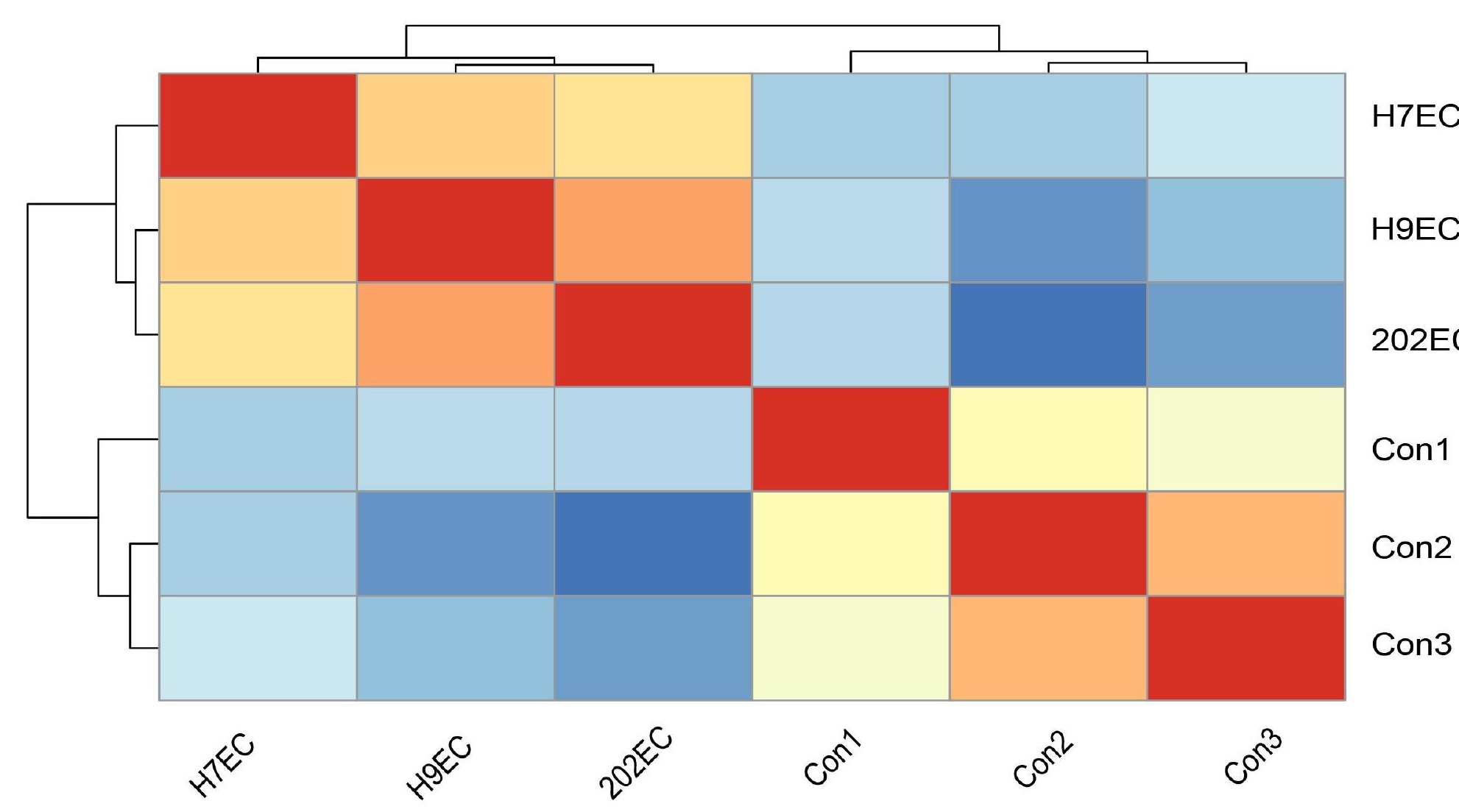

PSC-derived EPCs (vs normal EPCs)

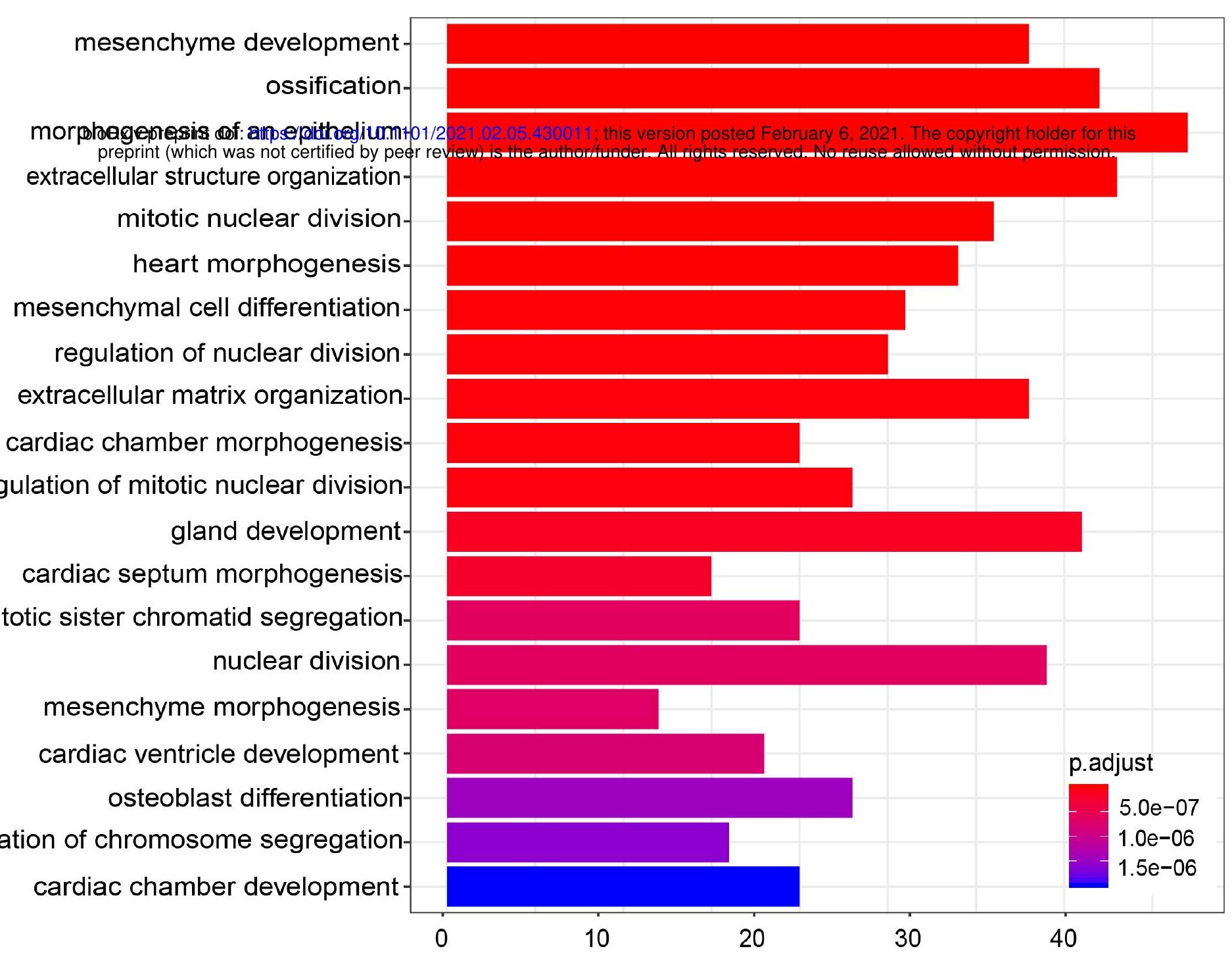

PSC-derived EPCs (vs IPAH-EPCs)

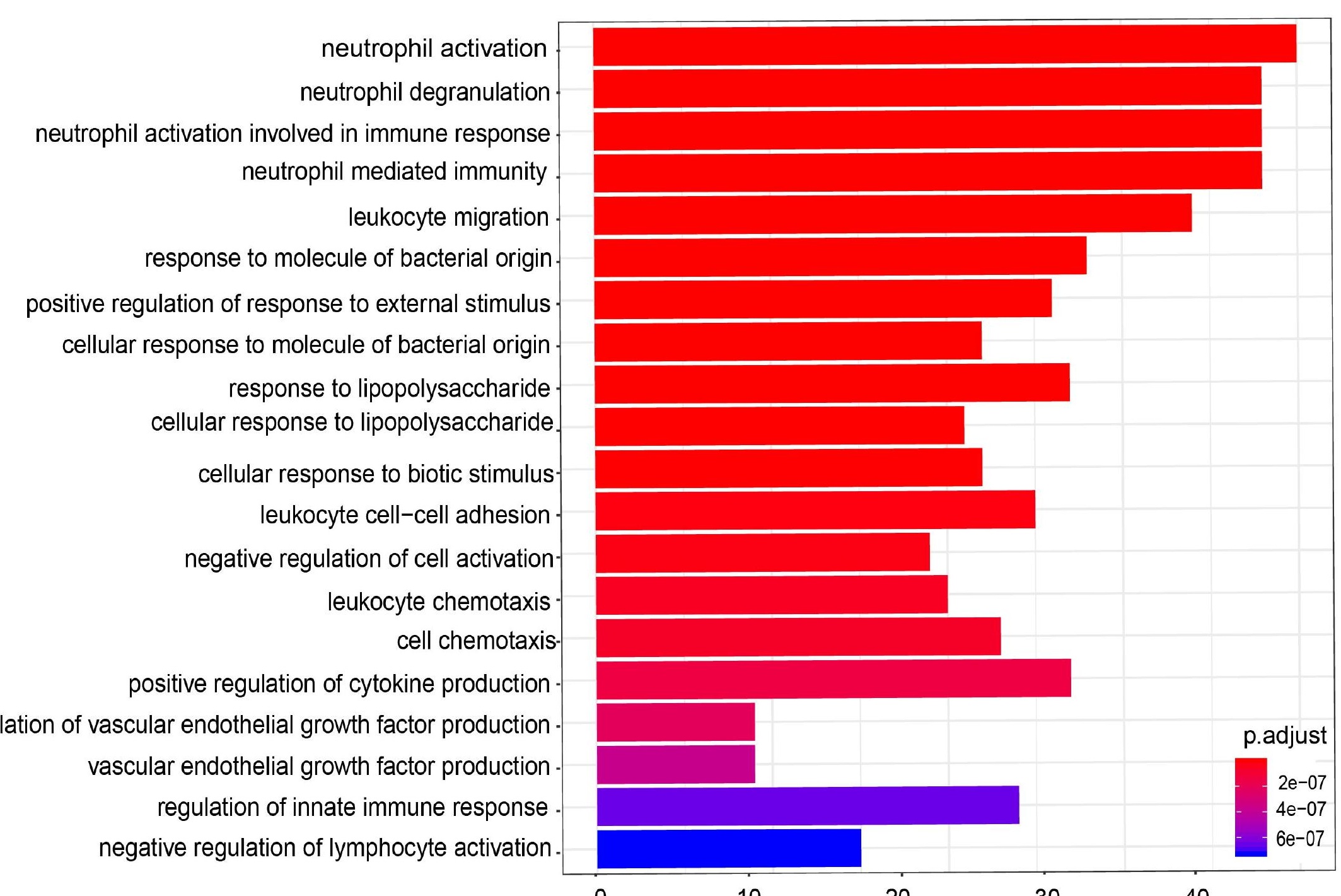

MKi67

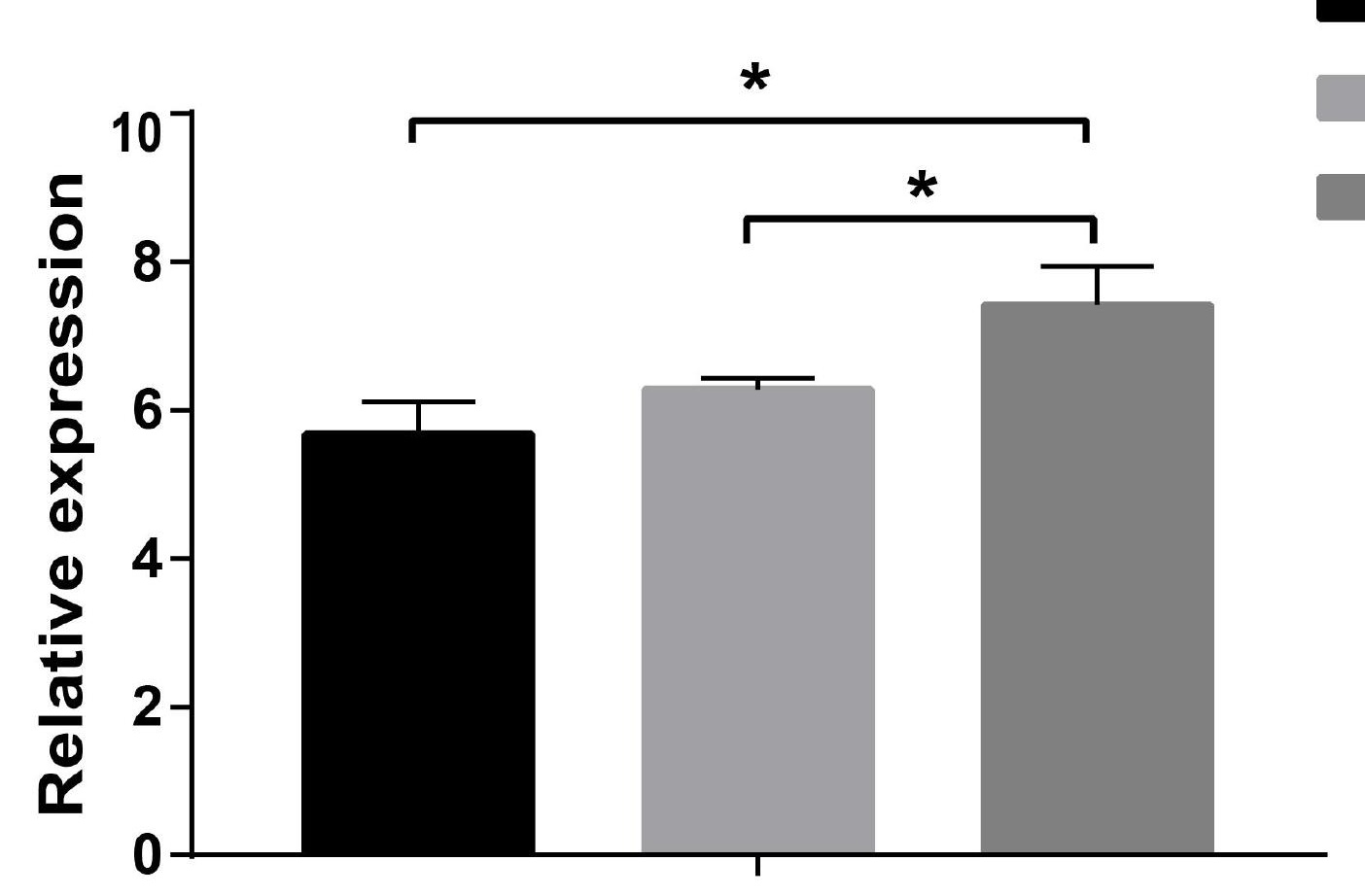

normal EPCs

PSC-derived EPCs

IPAH-EPCs
D

IPAH-EPCs (vs normal EPCs)

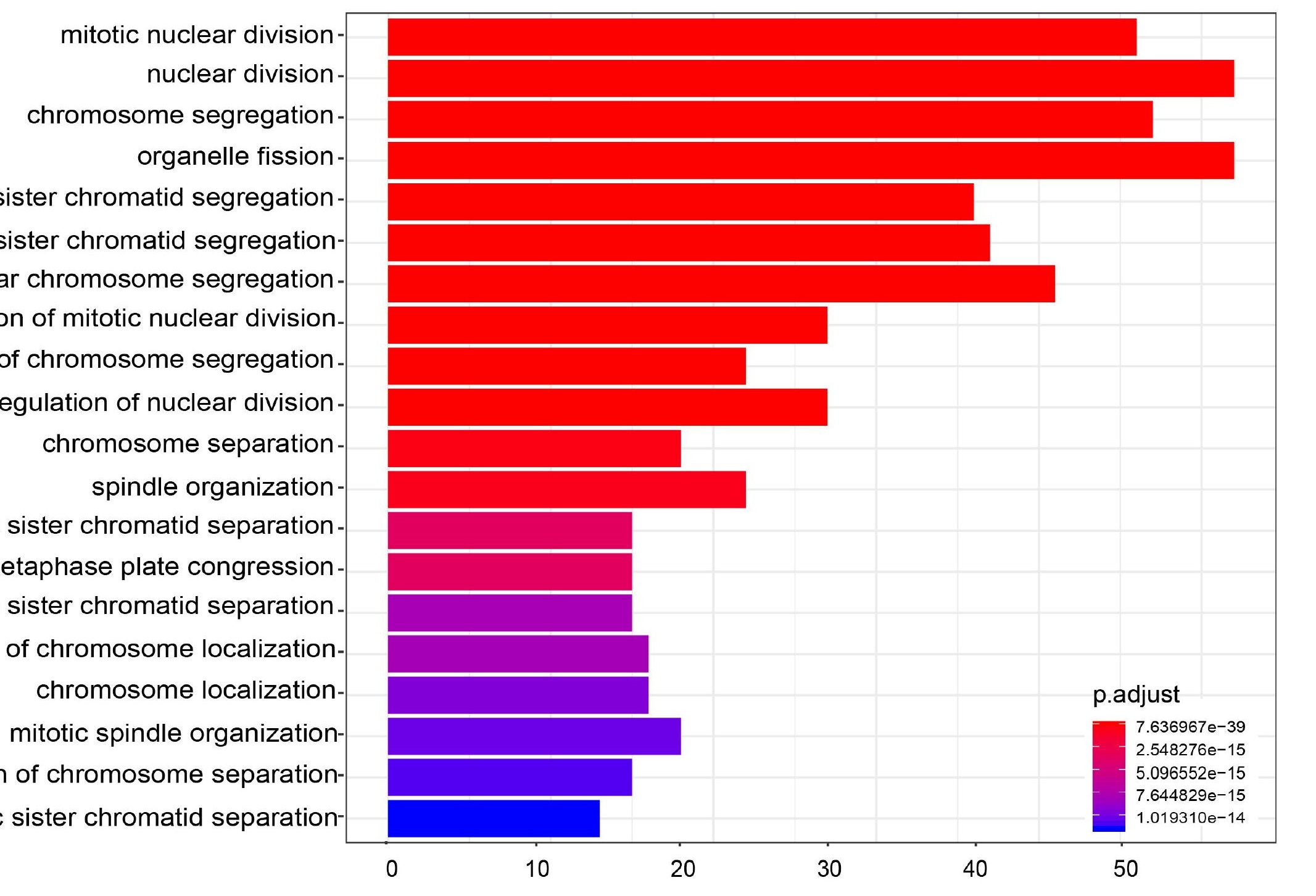

normal EPCs (vs IPAH-EPCs)

F

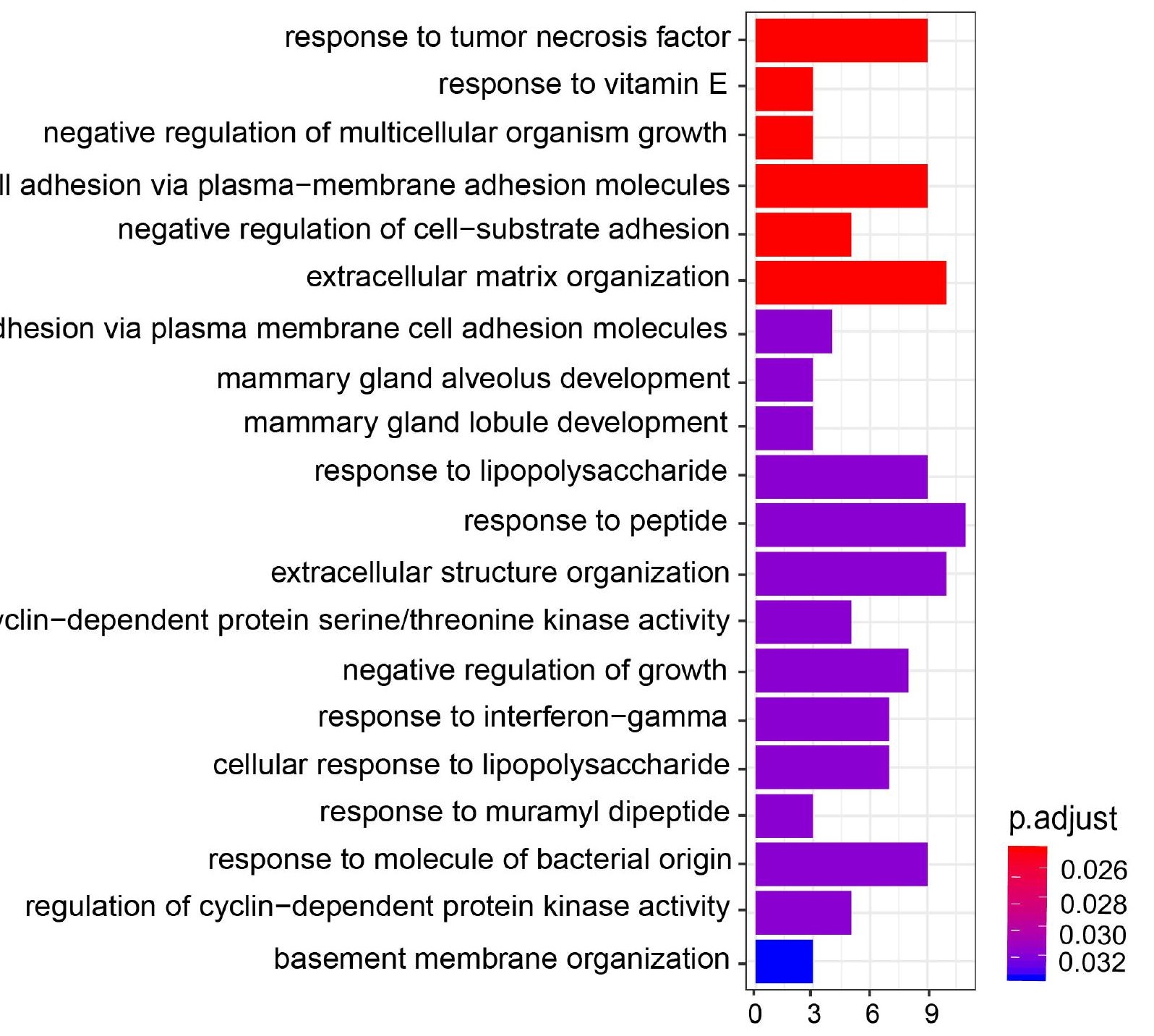

